\title{
أساليب وأهداف التنظيمات الإرهابية عبر شبكة الإنترنت وتأثيرها على الأهن الدولي
}

\section{خيرالدين العايب}

دكتوراه في العلاقات الدولية- الجزائر

Khiredine12@hotmail.com 
www.refaad.com
المجلة الدولية للدراسات القانونية والفقهية المقارنة

International Journal of Legal and Comparative Jurisprudence Studies (LCJS)

Journal Homepage: https://www.refaad.com/views/LCJS/Home.aspx

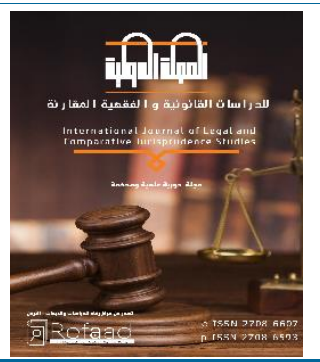

\title{
أسـاليب وأهداف التنظيمات الإرهابية عبرشبكة الإنترنت وتأثيرها على الأمن الدولي
}

\author{
خيرالدين العايب \\ دكتوراه في العلاقات الدولية- الجزائر
}

Khiredine12@hotmail.com

DOI: https://doi.org/10.31559/LCJS2021.2.2.2 2021/7/24 2021/5/12 مراجعة البحث: 2021/6/20 قبول البحث البحث: 2012

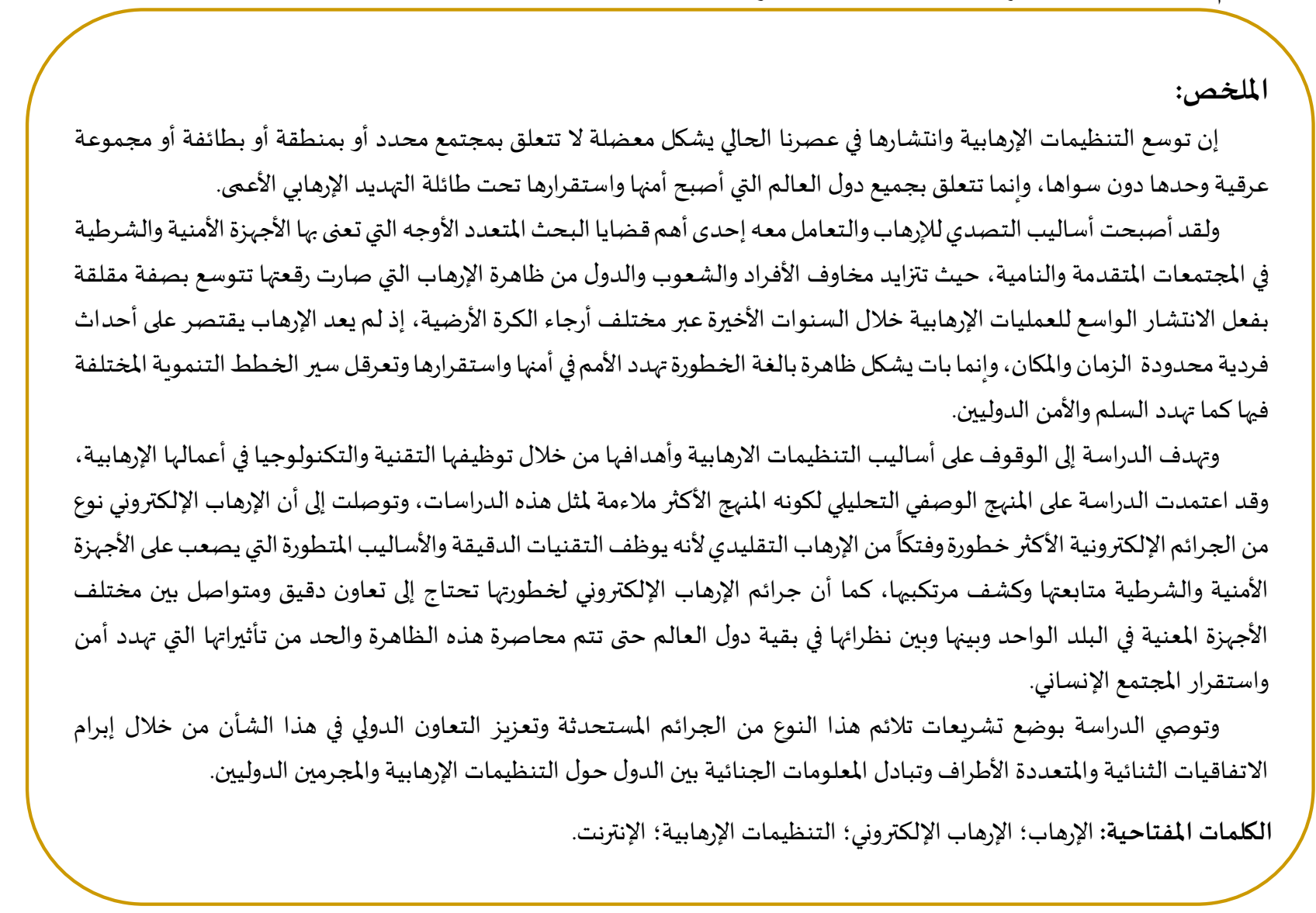

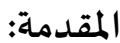

أدت الثورة التقنية في مجال الحاسب الآلي إلى تغيّرات جوهرية وتحولات شملت حياة الأفراد والمنظمات والحكومات، والتكنولوجيا المتطورة التي

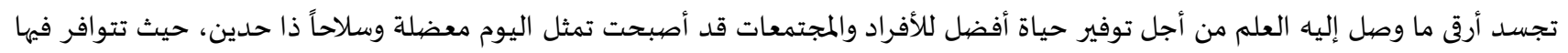

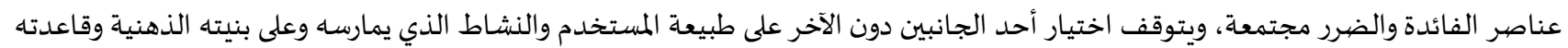
التربوية ومخزونه الثقافي والمعرفي وإلى منظومة القيم التي تحكم سلوكها. 


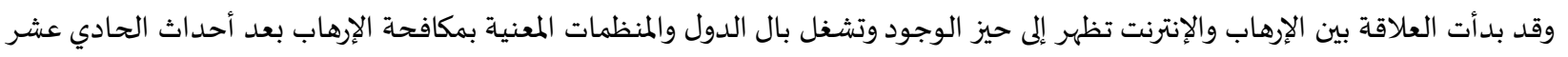

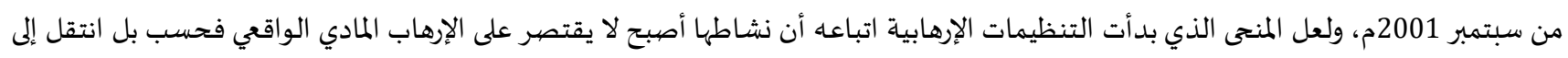

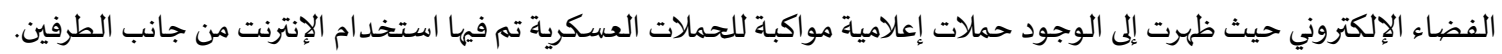

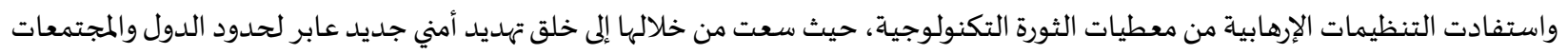

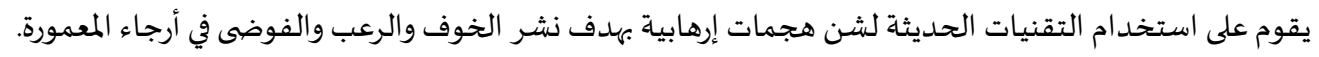
إشكالية الدراسـة: تعالج الدراسة إشكالية على درجة كبيرة من الأهمية والخطورة تتمثل في استخدام الإنترنت وتطبيقاته المختلفة للمساس بحياة البشر وأمن

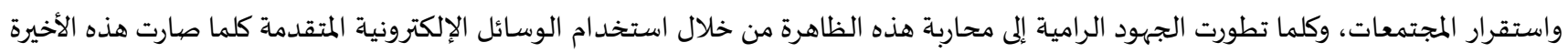

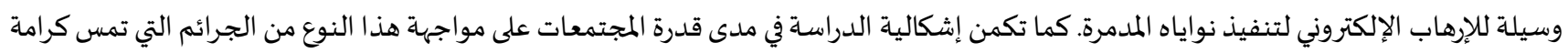

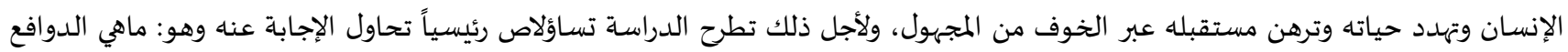

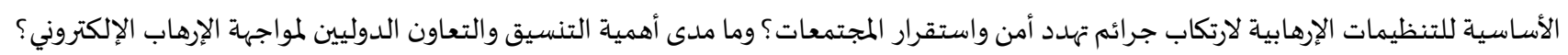

\section{أهمية الدراسـة: \\ تنقسم الدراسـة إلى قسمين: \\ • • ب الأهمية العلميية:}

تظهر أهمية الدراسة في محاولتها استكشاف وتحديد معالم ظاهرة الإرهاب الإلكتروني التي تقوم على مستحدثات الإنترنت وتطبيقاته المتعددة كالبريد الإلكتروني والمنتديات وغرف الدردشة ومواقع التواصل الاجتماعي، وهي المواقع التي نستخدمها في حياتنا اليومية بشكل كبير، والتي نعرّض أنساتئ أنفسنا

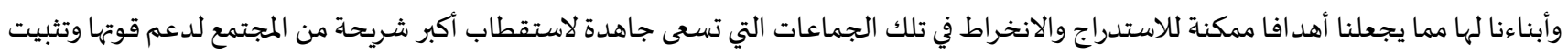
مكانتها.

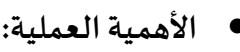
كما تكمن أهمية هذا الموضوع في إبراز الجرائم التي ترتكبها التنظيمات الإرهابية عبر شبكة الإنترنت وأساليب مواجهتها، وفي مدى خطورة هذه

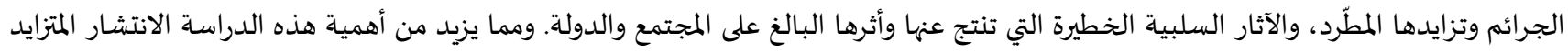

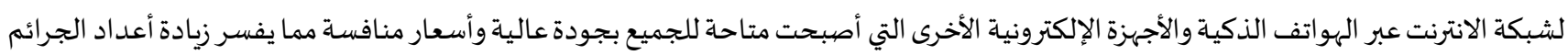

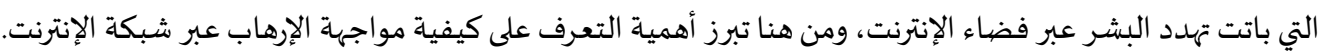

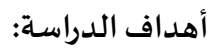

ترمي الدراسـة إلى تحقيق الأهداف التالية: 1. تحديد مفهوم الإرهاب عبر شبكة الإنترنت

2. ـ طرق التهديد والترويع عبر الإنترنت. 3. صور وأشكال الإرهاب عبر الإنترنت. 4. دوافع التنظيمات الإرهابية من توظيف شبكة الإنترنت.

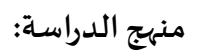

للإجابة على التساؤلات المطروحة سيتم الاعتماد على المنهج الوصفي التحليلي من خلال التحليل وربط الأسباب بالنتائج مما يسمح بمعرفة مختلف

جوانب الظاهرة محل الدراسة عبر عرض مختلف الرؤى المتعلقة بمواجهة الإرهاب عبر شبكة الإنترنت. تسـاؤلات الدراسـة: تحاول الدراسة الإجابة على التساؤلات التالية:

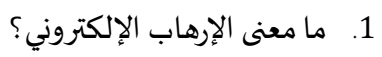

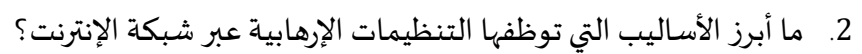

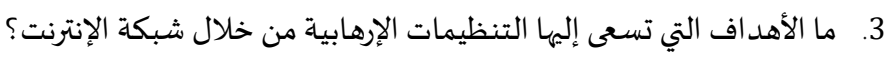

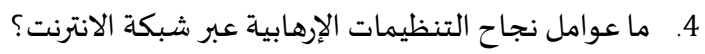


تقسيم الدراسـة:

قسمت الدراسة إلى ثلاث مباحث، خصصينا المبحث الأول لدراسة المفاهيم الأساسية للإرهاب من خلال مطلبين اثنين، تناول المطلب الأول تعريف

الإرهاب في اللغة وتناول المطلب الثاني تعريف الإرهاب اصطاحثلاً خصئاً.

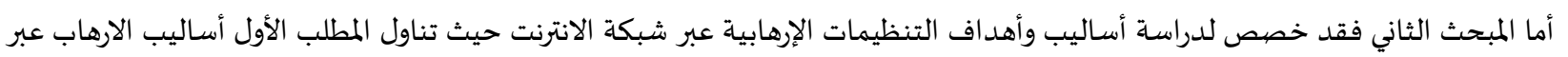

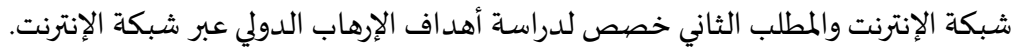

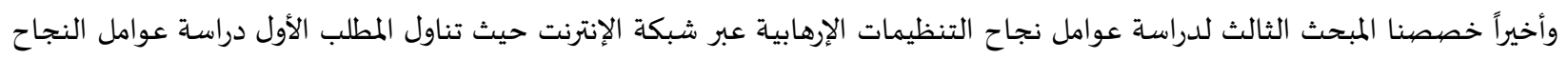
الناتجة عن خصائص الإرهاب والمطلب الثاني درسنا فيه عوامل النجاح المرتبطة بطبيعة وسمات المجات المبرم المعلوماتي عبر شبكة الإنترنت.

\section{المبحث الأول: ماهية الارهاب الإلكتروني}

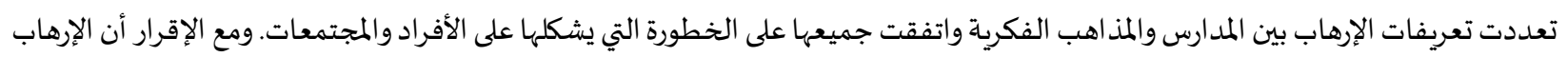

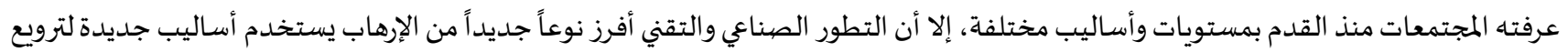
البشر.

المطلب الأول: تعريف الإرهاب لغة أولاً: معنى الإرهاب:

لم يرد في المعاجم العربية القديمة ذكر لكلمة إرهاب ولا لأي تفسير لمعناها، وينطبق ذلك على كلمة إرهابي، وفي اللغة العربية تعرف الرهبة بأهها ذلك الخوف المترافق مع الاحترام.

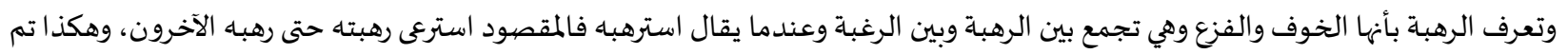

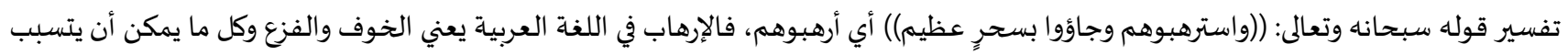

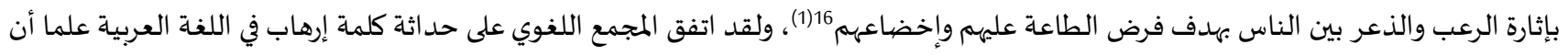

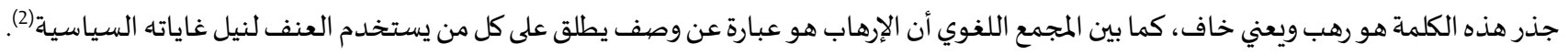

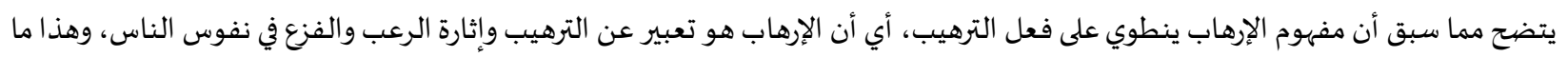
يميز جريمة الإرهاب عن غيرها من الجرائم الأخرى.

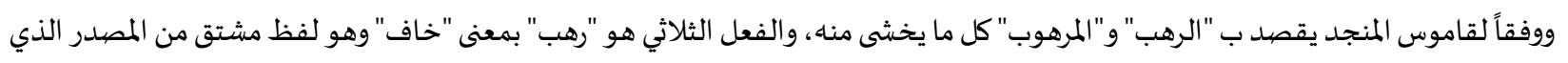

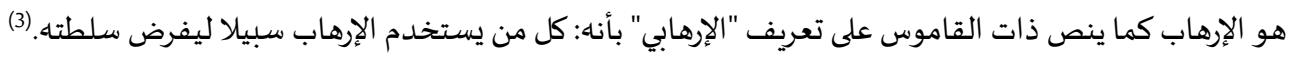

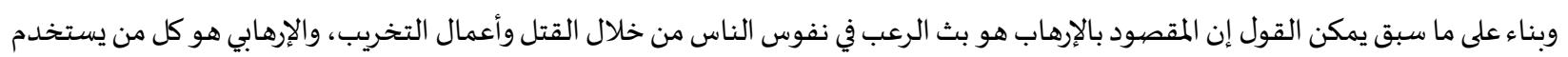

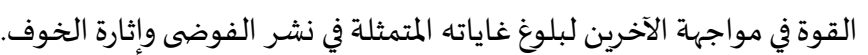

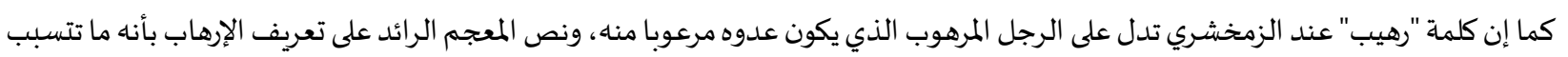

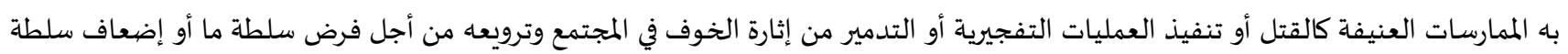
أخرى. (4) وفي اللغة العربية، أصل كلمة إرهاب هو الفعل "رهب" وهو بمعنى خاف وبابه "أرهبه" و "استرهبه" بمعنى أخافه ويقصيد ب "الرهب" التعبد ومصدره

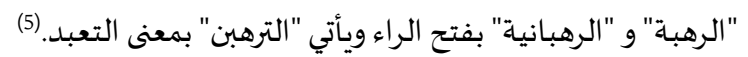

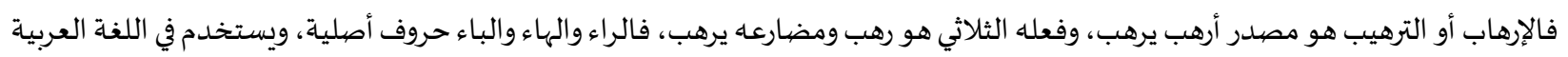

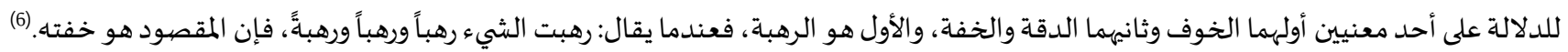

1 د. رشدي عليان. الدين والإرهاب. بغداد: منشورات منظمة المؤتمر الإسلامي الشعبي، بحوث فكرية للسنة الثالثة، كلية الشريعة، 1998م، ص23.

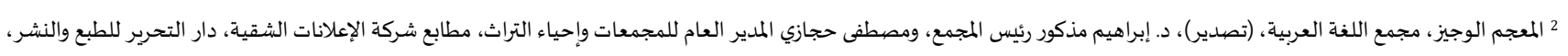

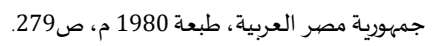
3قاموس المنجد.القاهرة:دار الشروق، 1969 م، ص ص 282.

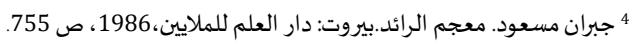

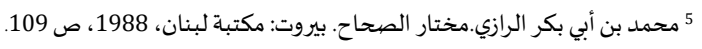

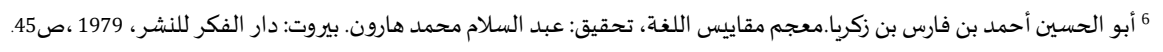


ومنه يتضح لنا أن العديد من المعاجم اللغوية جاءت متفقة في تلازم مصطلح الإرهاب مع العنف، كما أنها جاءت متفقة من ناحية أن الإرهاب يهدف

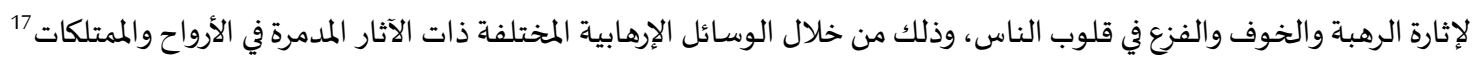

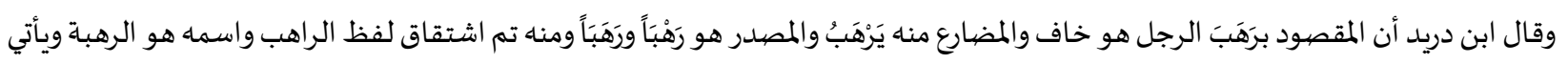

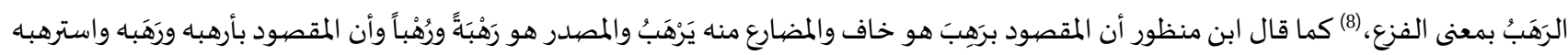

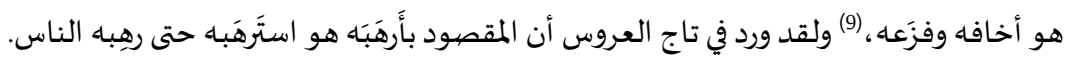

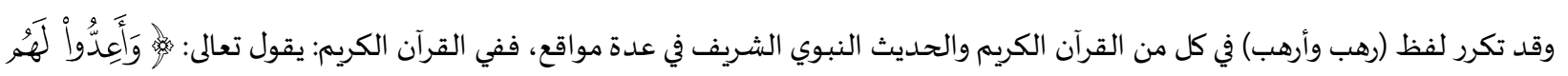

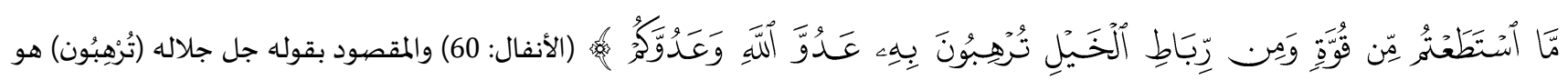
تخيفون أو تثيرون مخاوف. (10) ونص توضيح للفخر الرازي على أن العبرة من إعداد القوة ومن إعداد رباط الخيل هي أنه إذا علم الكفار أن المسلمين قد تهيؤوا للجهاد ولقتالهم

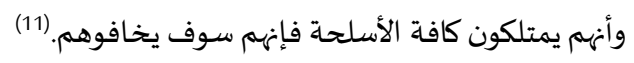
ومن التعريفات اللغوية يتضح لنا أن جميع ما ورد من تعريفات للإرهاب إنما تتمحور حول فكرة واحدة هي أن الإرهاب هو تعبير عن إثارة الخوف والرعب والفزع في قلوب الناس، أي أن هناك إجماع فقهي ولغوي حول الغرض من الإرهاب، فالغرض من الإرهاب يتمثل في إثارة الفزع وإزهاق الأرواح وتدمير الممتلكات ونشر الفوضى. والرعزي

وبعد استعراض مواقف المعاجم القديمة والحديثة من لفظ الإرهاب توصلنا إلى مايلي:

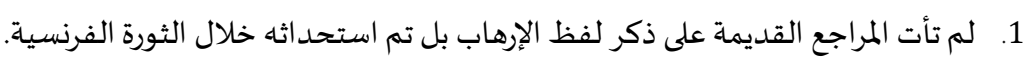

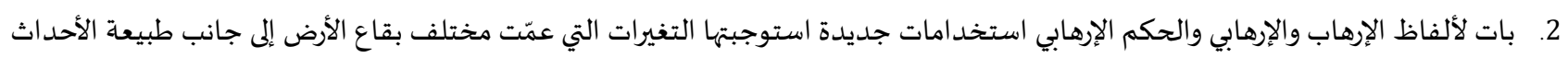

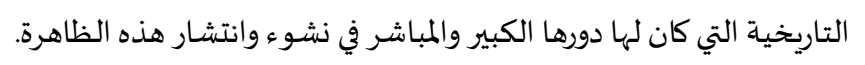

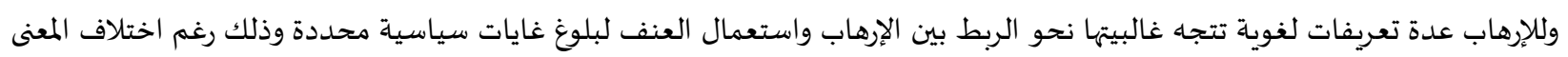

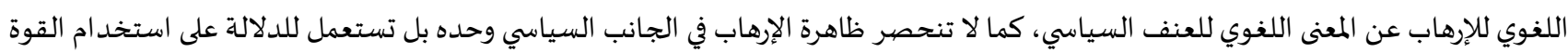

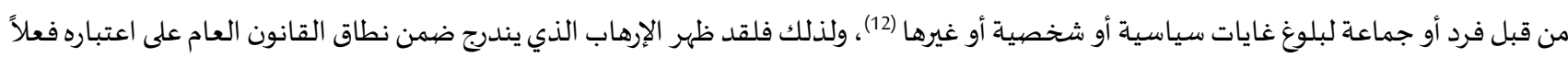
إجرامياً تعاقب التشريعات الجنائيّة مرتكبيه. (13)

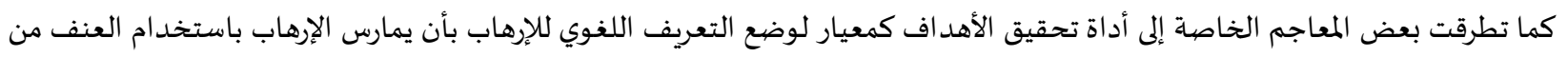
قبل جماعة منظمة أو حزب ضد المعارضين لأهدافهما (14).

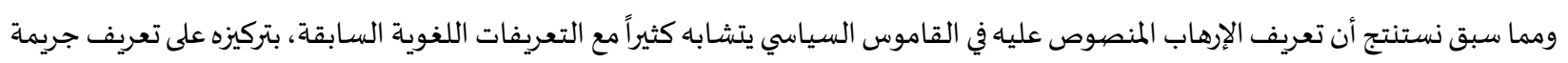

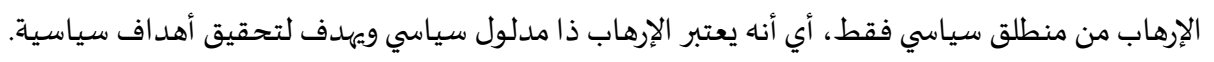

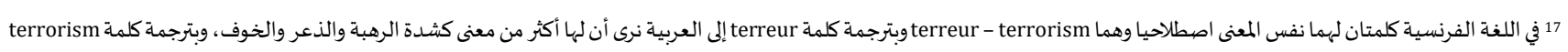

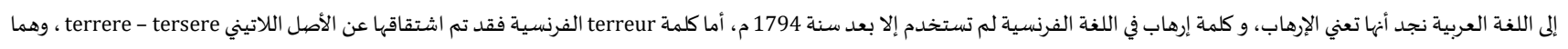
فعلان يوظفان بمعنى يرتعد أو يرتجف.

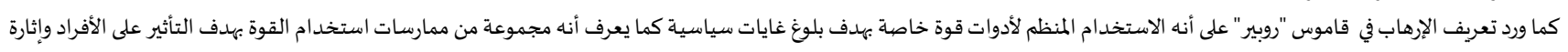

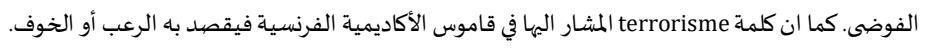

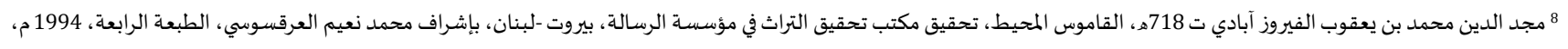

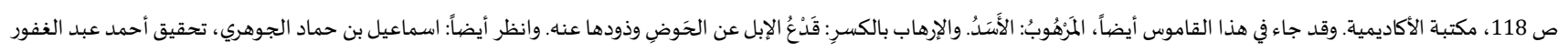

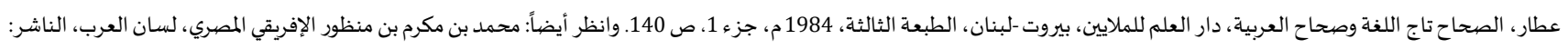

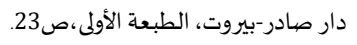

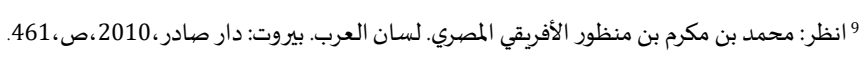
10 معاني القرآن الكريم، 166/3. 186/15 11 11 تفسير الكبير

12 د. نبيل أحمد حلمي. الإرهاب الدولي وفقاً لقواعد القانون الدولي العام.القاهرة: دار النهضة العربية، 1988 م، ص ص 29.

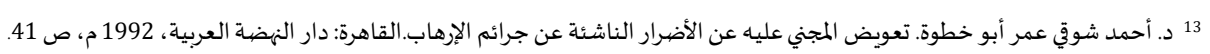
14 لمزيد من التفاصيل، انظر معجم العلوم الطبيعية، مادة الإرهاب. القاهرة: الهيئة المصرية للكتاب، 1975 ، ص ص 27. 
المطلب الثاني: معنى الإرهاب في الاصطلاح:

لم يرد للإرهاب تعريف في الاصطلاح الشرعي لدى العلماء السابقين حيث كان أول استعمال لله عقب الثورة الفرنسية سنة 1789 مما يدل على أنها منبثق عن الفكر الأوروبي ويثبت بطلان ادعاءات اتصياف الإسلام به، ولم يتفق العلماء والمفكرون في مختلف بقاع الأرض بأديانهم المختلفة على تحديد

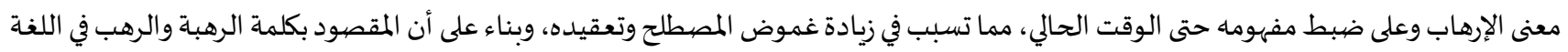
هو الخوف والاضطراب والفزع يكون المقصود بالإرهاب هو كل فعل اعتداء يتسبب في إثارة مخاوف الآخرين، ونشر الاضطراب بينهم، أيا كانت أدوات

تنفيذه ونوعية مرتكبياه.

وقد قيل في تعريف الإرهاب أنه كل فعل إجرامي عمدي تكون بواعثه سياسية باستثناء زمن الحرب، حيث يعرف بأنه طريقة عسكرية يتبعها فرد أو

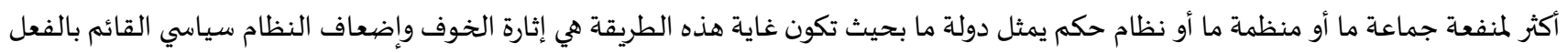

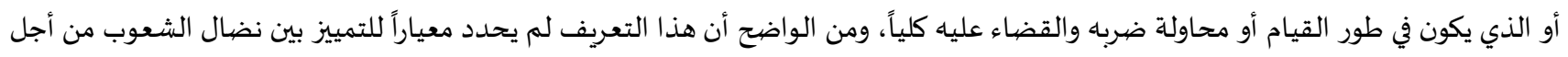
التحرير وتقرير المصير وبين الإرهاب، حيث يختلف المفهومان عن بعضهما البعض كثيراً، ويؤكد رجال السياسة على الاختلاف بين المفهومين ويحرصيون

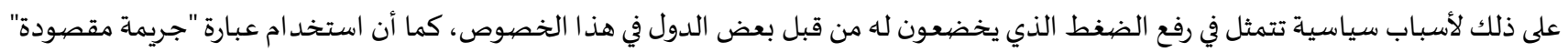
يدل على هذا المعنى، حيث أن حق تقرير المصير والكفاح المسلح لنيل هذا الحق هو حق اعترفت باء العديد من المواثيق الدولية للشعوب والأممروفي مقدمتها

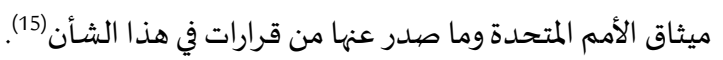

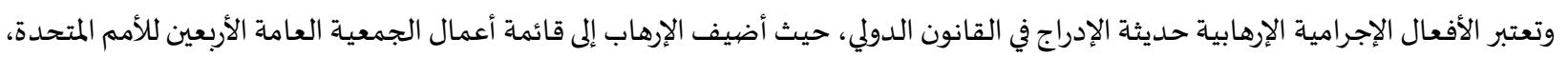

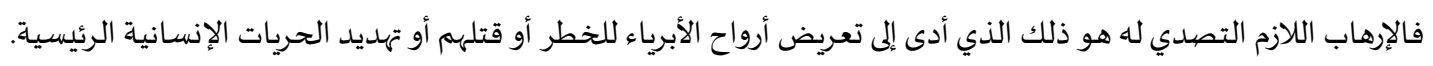

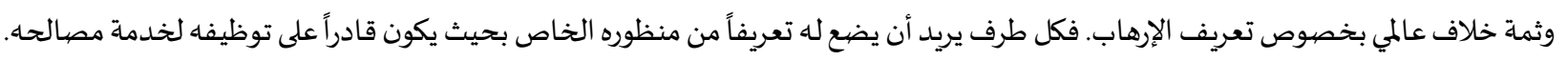

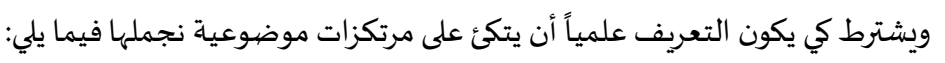

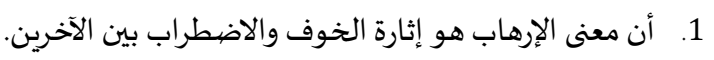

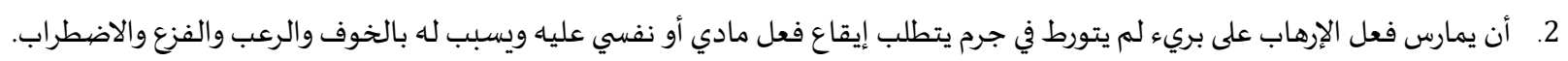

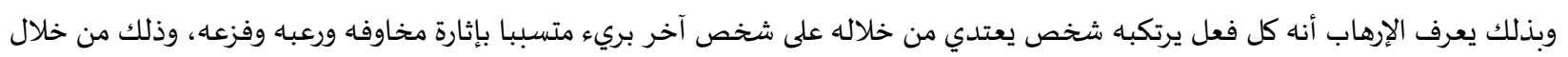

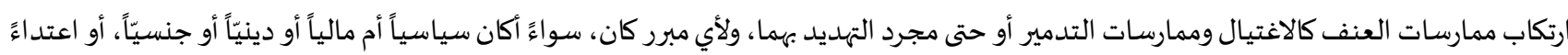

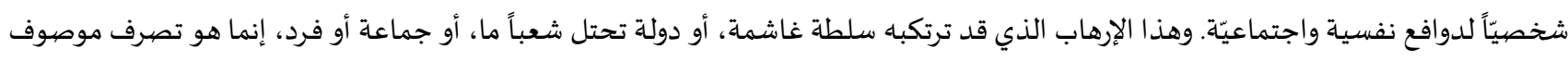

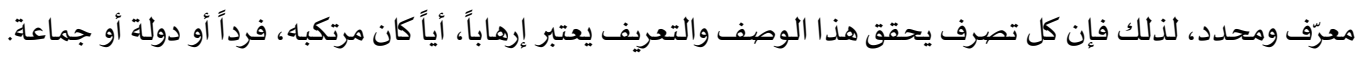

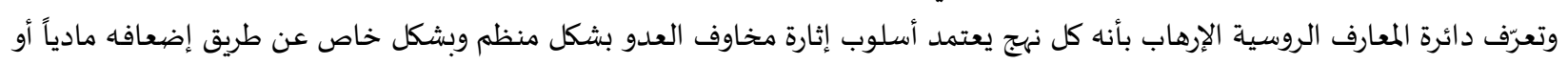

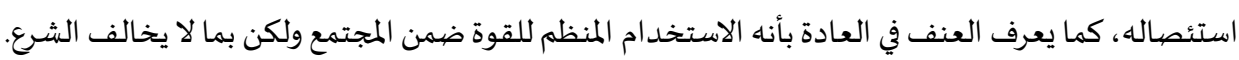

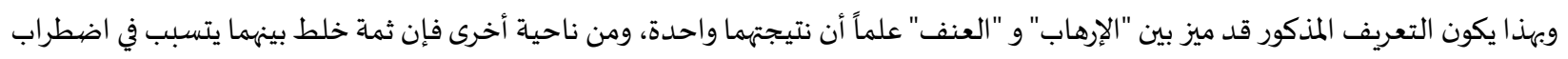

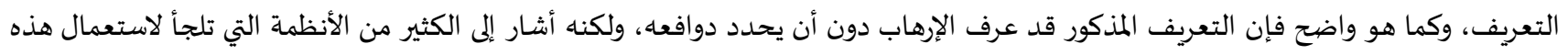

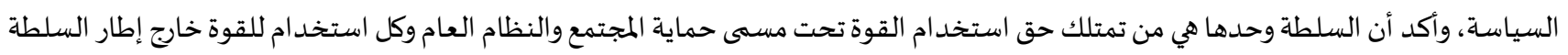

يعتبر عنفا.

كما يعرف الإرهاب في القاموس السياسي بأنه كل محاولة لإثارة الخوف لغايات سياسية وهو أداة تستعملها الحكومات المستبدة لإجبار الشعوب

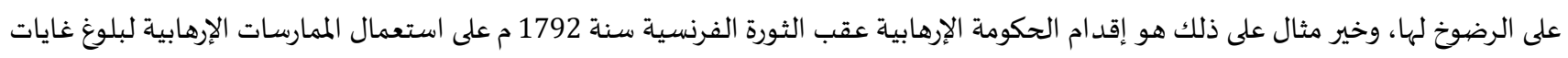

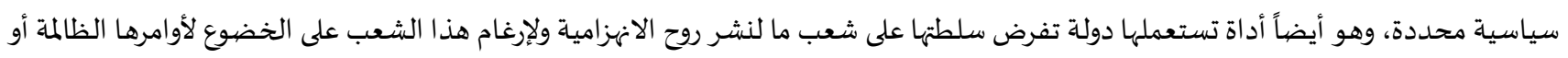

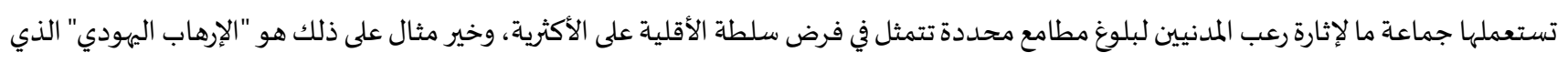

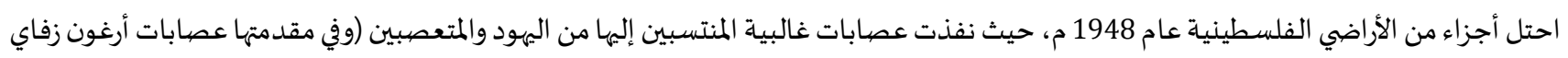

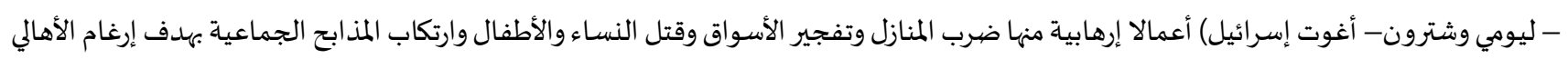

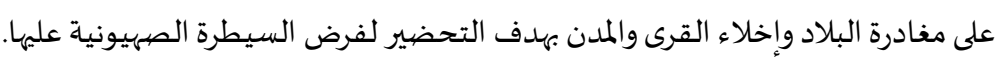

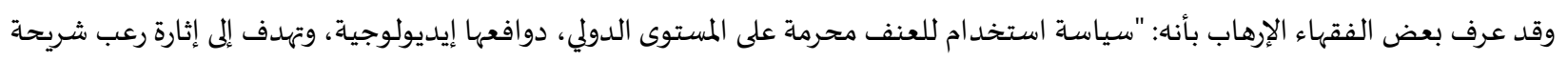

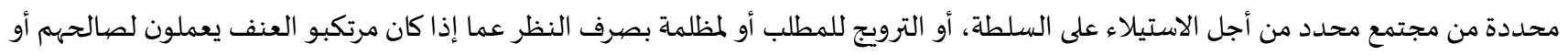
لصالح دولة ما"(16).

15 د. محمد عزيز شكري، د. أمل يازجي.الإرهاب الدولي والنظام العالمي الراهن. دمشق: دار الفكر 2012 ، ص70-70.

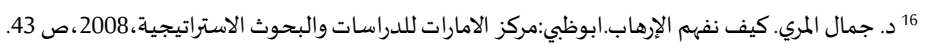


كما أن له تعريفاً آخر ينص على أن الإرهاب هو كل استعمال مقصود للقوة بشكل غير مشروع للاعتداء على الأفراد أو على ممتلكاتهم، لتخويفهم بهدف بلوغ غايات معينة(17) وبعد ما سبق ذكره من تعريفات يتوصل الباحث إلى أن الإرهاب هو مجموعة من الممارسات التي تستعمل فيها القوة بغية تخويف الناس وتتسبب

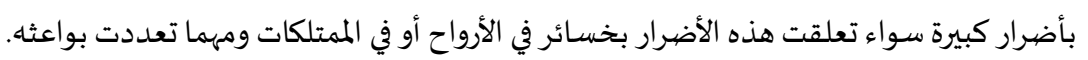

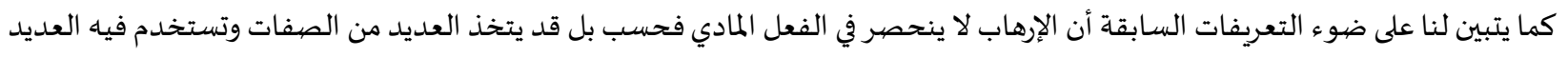

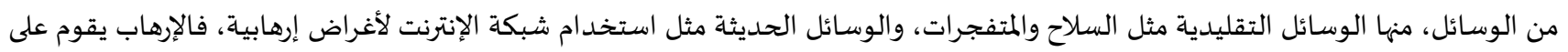

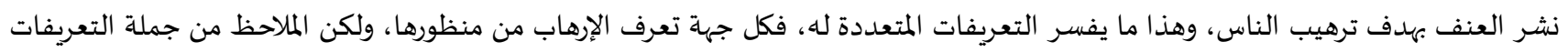

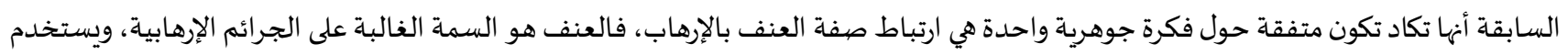

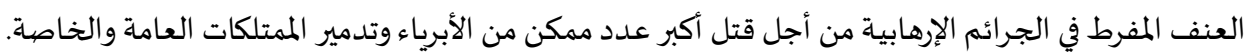

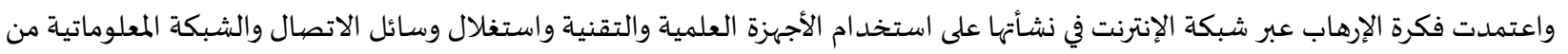
أجل تخويف وترويع الناس وإلحاق الضرر بهم.

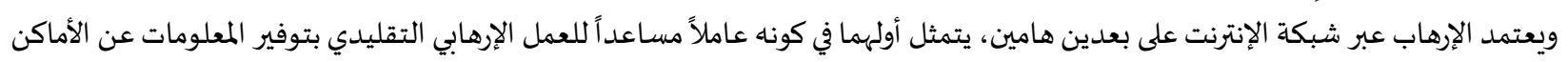

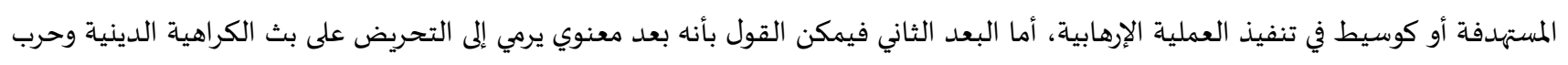

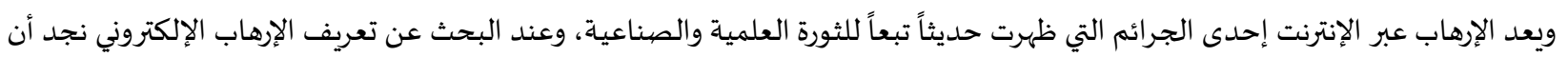

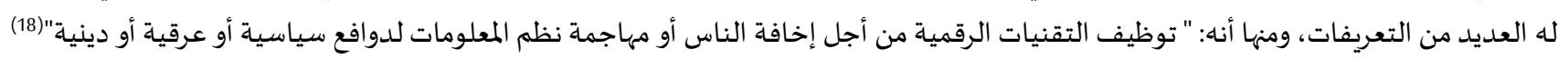

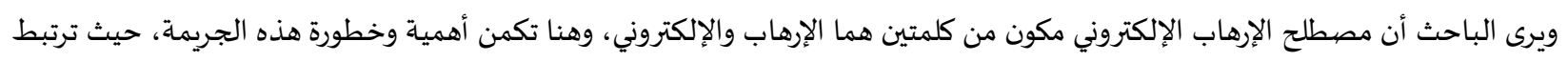

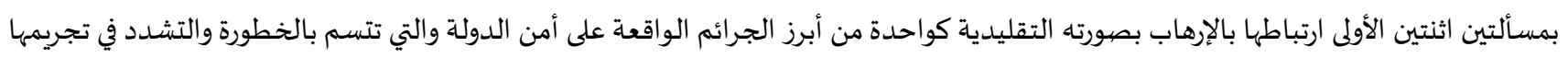

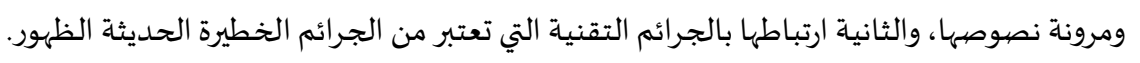

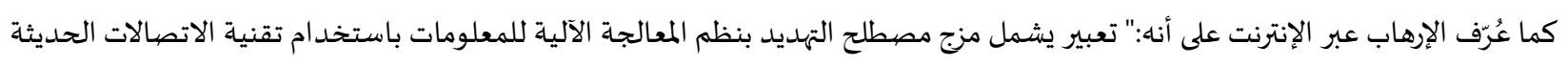
(الإنترنت)

وعرف أيضاً بانه" مهاجمة البنية التحتية للموقع أو استخدام التقنيات الرقمية لمهاجمة نظم المعلومات لدوافع سياسية أو دينية أو بهدف تخويف طرف آخر" (20) وعرف أيضاً على أنه" هجوم مدبر بدوافع سياسية ضدد المعلومات أو أنظمة الكمبيوتر أو برامج الكمبيوتر أو البيانات التي ينتج عنها عنف ضدد أي

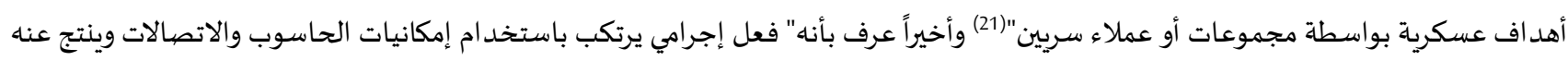

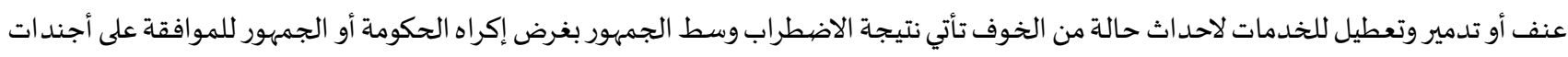
سياسية أو اجتماعية أو ثقافية". (22)

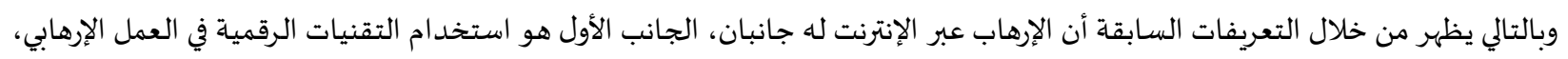

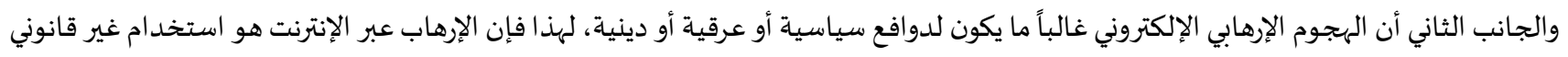

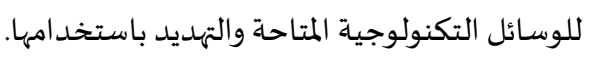

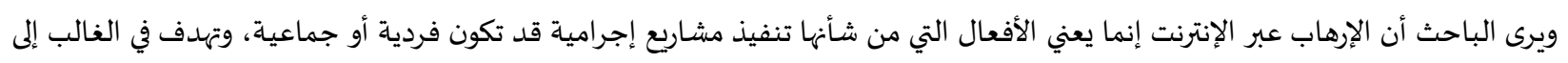

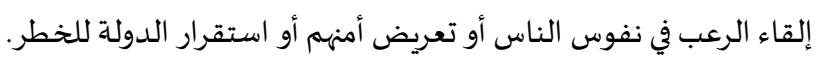

17 د. سامي جاد عبد الرحمن واصل. إرهاب الدولة في إطار القانون الدولي العام. الإسكندرية: منشأة المعارف، 2003 ، ص ص 52.

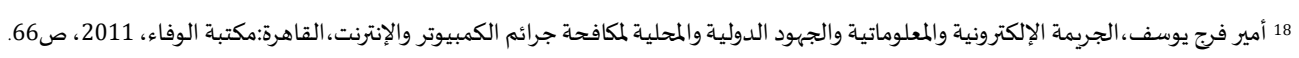

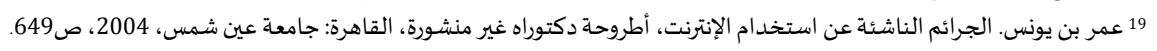

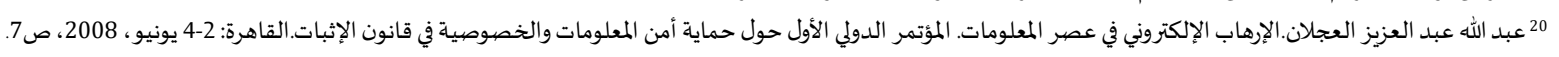

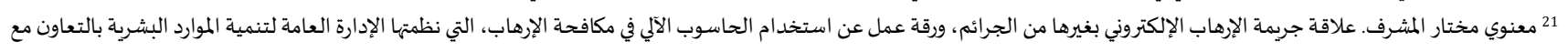

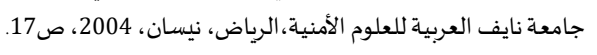

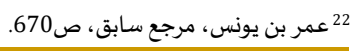


المبحث الثاني: أساليب وأهداف التنظيمات الإرهابية عبرشبكة الإنترنت

تتبع التنظيمات الارهابية العديد من الاساليب للوصيول إلى أهد افها وهي غير مبالية بخطورة أفعالها على السلموالأمن الدوليين، وتعتقد أن وسائلها مشروعة ومباحة من الناحية القانونية والدينية. ألمطلب الأول: الأساليب العامة للإرهاب الإلكتروني

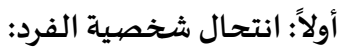

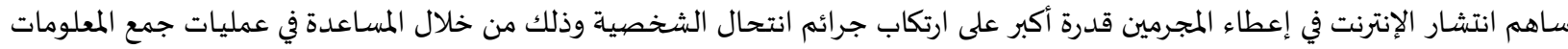

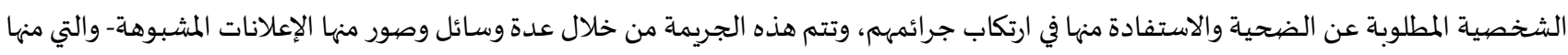

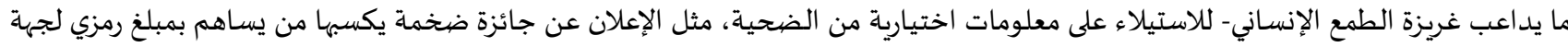

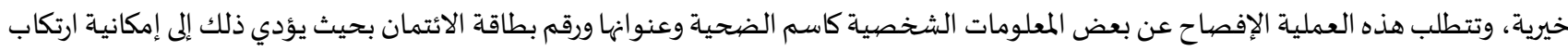

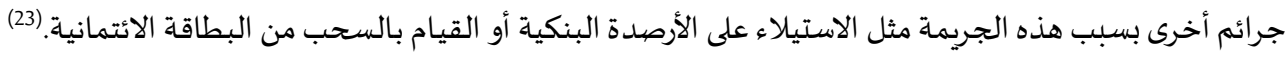

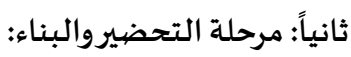

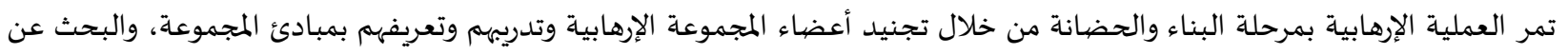

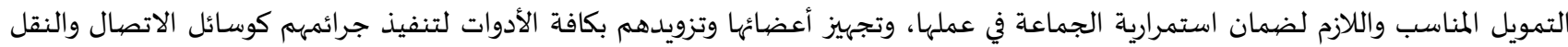

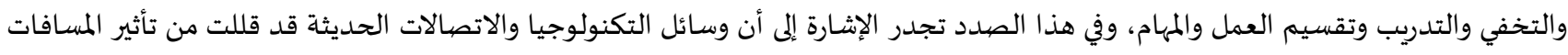

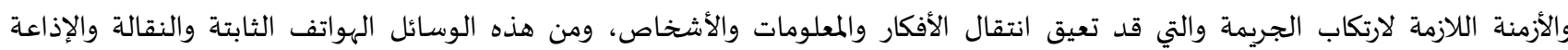
والتلفزيون.

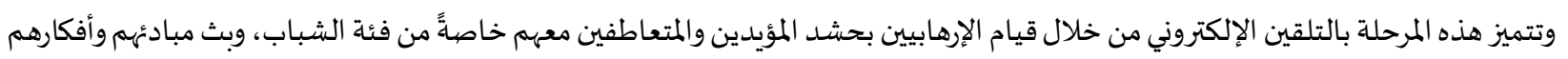

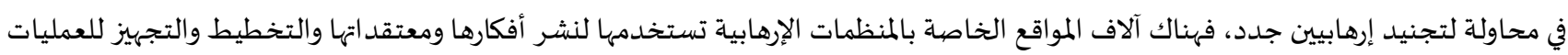

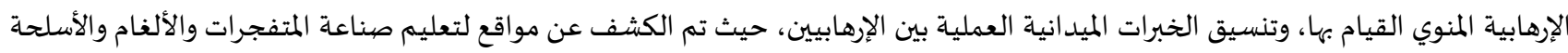

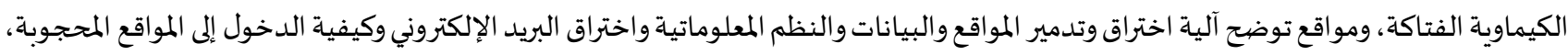

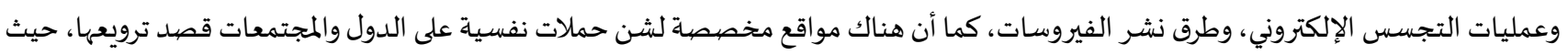

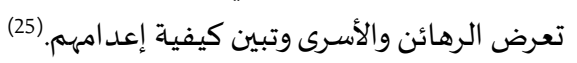
ثالثًاً اقتحام المو اقع الإلكترونية وتدميرها:

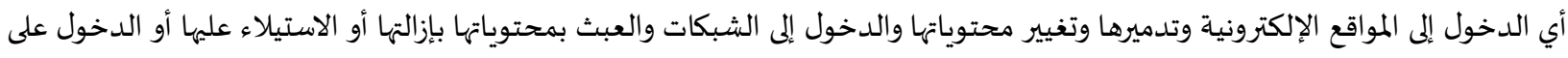

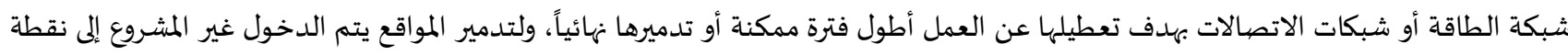

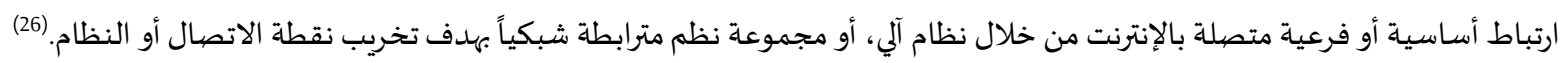

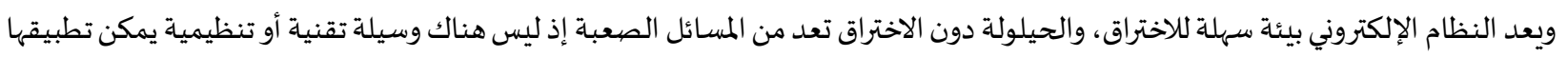

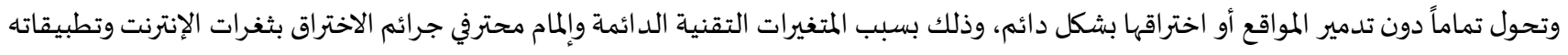

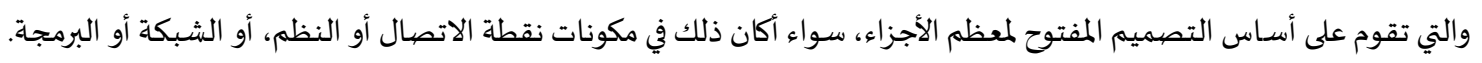

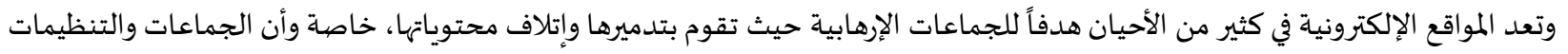

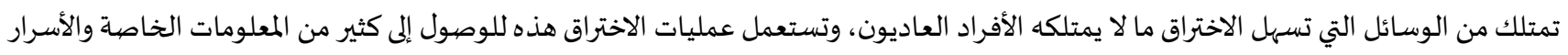
الشخصية واختراق الخصهوصية.

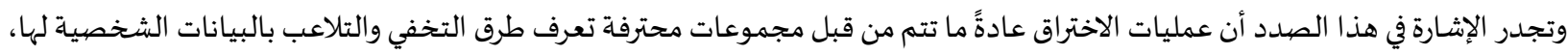

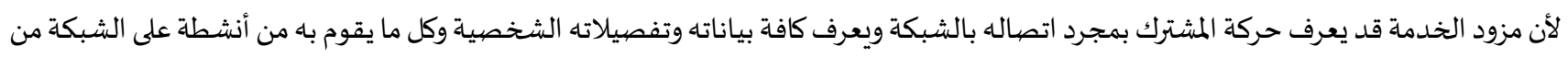

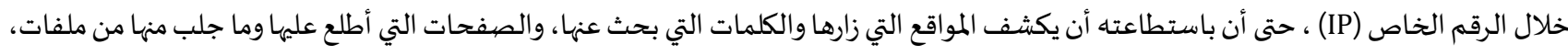

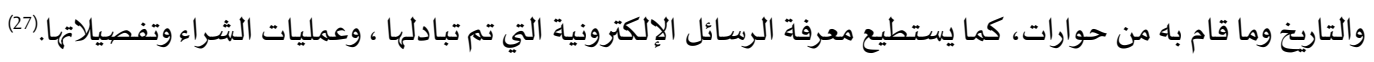

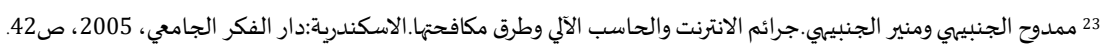

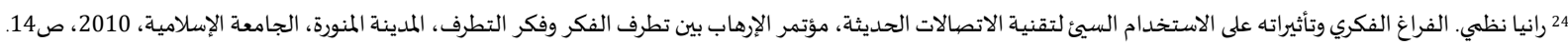
25

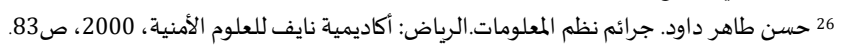
27 عبد الرحمن بن عبد الله السند. وسائل الإرهاب الإلكتروني: حكمها في الإسلام طرق مكافحتهتها. الرياض: جامعة الإمام محمد بن سعود الإسلامية، 2005، ص24. 
وهناك عدة طرق للاختراق وتدمير المواقع نذكر منها ما يلي:

الإغراق بالرسائل: وهي ربما تكون طرق مستقلة بذاتها لتنفيذ السلوك الإجرامي في جرائم الإنترنت.

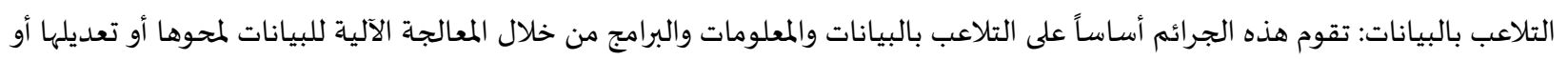

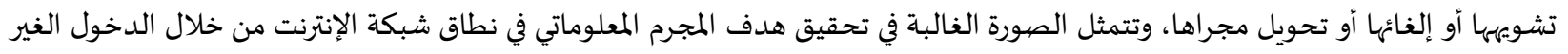

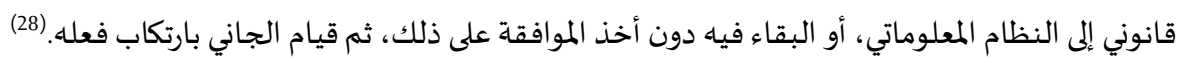

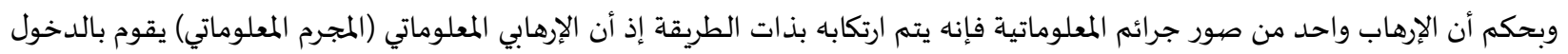

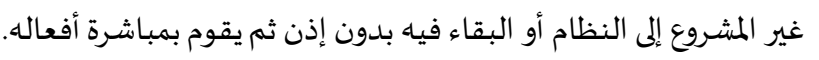

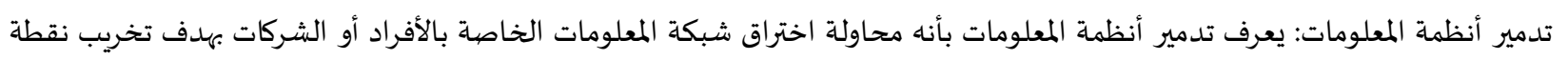
الاتصال أو النظام عن طريق تخليق أنواع من الفيروسات الجديدة التي تسبب كثيراً من الضرر والشلل لأجهزة الكمبيوتر والمعلومات التي تم تخزينها

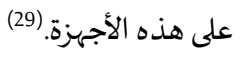
رابعاً: انتحال شخصية المو اقع:

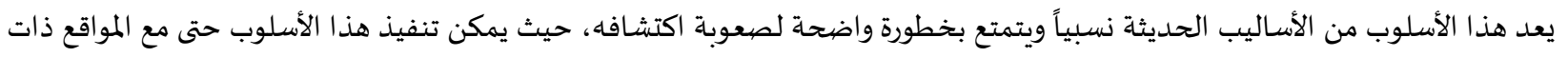

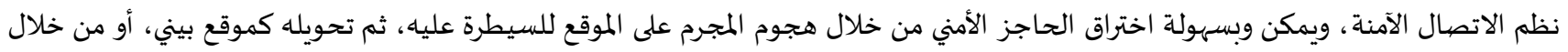

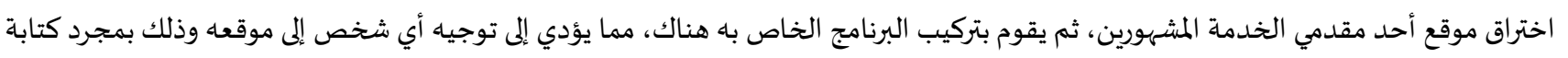
اسم الموقع الشهير. (30) خامساً: التهلديد عبر الإنترنت: التهديد أساساً عبارة عن أقوال وهذه الأقوال لا تعد جريمة ما لم تخرج الإنى الى العالم المادي، وفي الجرائم الإرهابية يجب توافر عنصر الترويع والتخويف

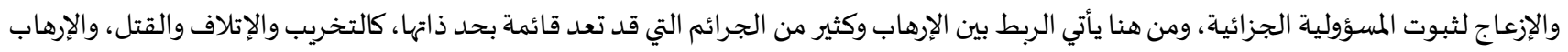
عبر الإنترنت. ويتخذ التهديد عبر الإنترنت عدة أشكال وصور كالتهديد بالقتل لشخصيات سياسية أو التهديد بالقيام بتفجيرات في مراكز سياسية أو تجمعات التهات رياضية أو التهديد بإطلاق فيروسات لإتلاف الأنظمة المعلوماتية في العالم. المطلب الثاني: الأهداف العامة للإرهاب عبرشبكة الإنترنت أولاً: يهدف الإرهاب عبر شبكة الإنترنت إلى تحقيق جملة من الأهداف غير المشروعة التي يمكننا بيانها في النقاط التالية:(32)

$$
\begin{aligned}
& \text { تخويف وترعيب الأشخاص والدول والشعوب. } \\
& \text { الإخلال بالنظام العام والأمن المعلوماتي. } \\
& \text { تعريض سلامة المجتمع وأمنه للخطر. } \\
& \text { هالإضرارر بالبنى المعلوماتياة التحتية والعمل على تدميرها. } \\
& \text { تهديد السلطات العامة والمنظمات الدولية وابتزازها. }
\end{aligned}
$$

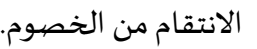

$$
\begin{aligned}
& \text { جذب الانتباه وإثارة الرأي العام. } \\
& \text { جمع الأموال والاستيلاء عليها. }
\end{aligned}
$$

المطلب الثالث: دو افع الإرهاب الدولي عبرشبكة الإنترنت

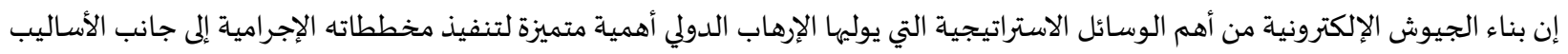

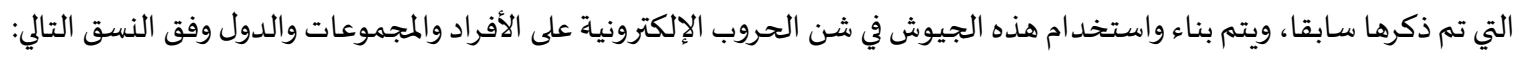

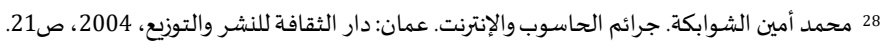

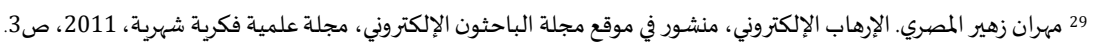

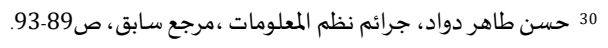

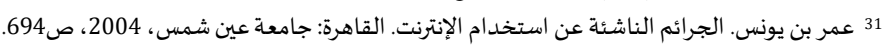

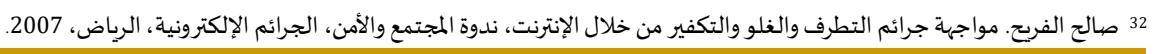


أولاً: تطوير الاستعدادات الهجومية:

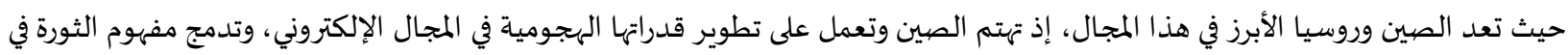

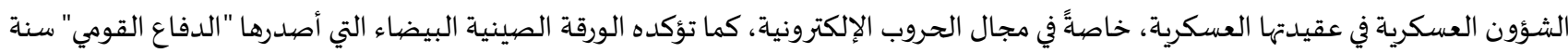

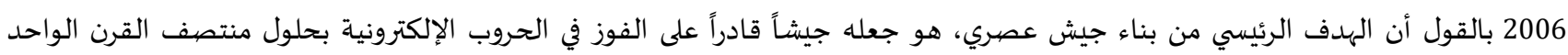

والعشرين. (33)

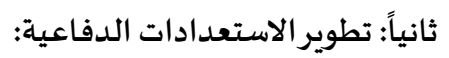

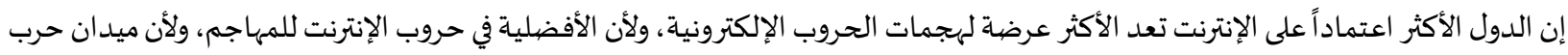

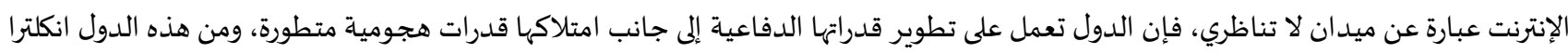

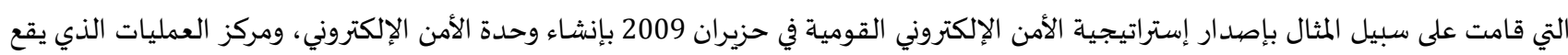

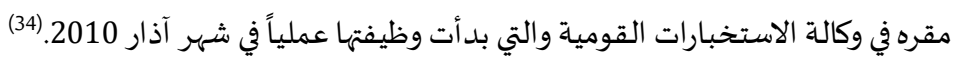

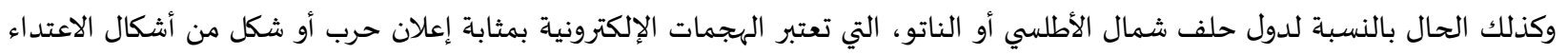

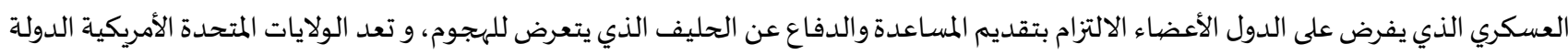

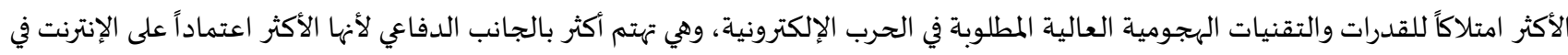

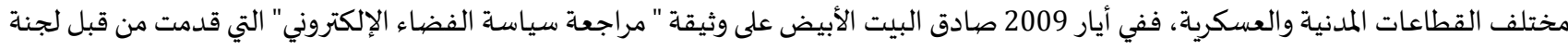

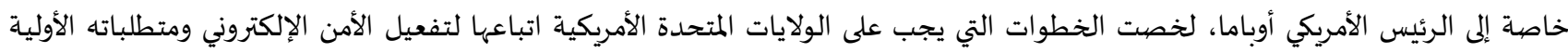
الأساسية.(35) وقد كشفت وكالة الاستخبارات المركزية الأمريكية عن مبادرة جديدة لمحاربة الهجمات الإلكترونية، وقامت في شهر مائرة مايو 2010 بإنشاء قيادة الإنترنت

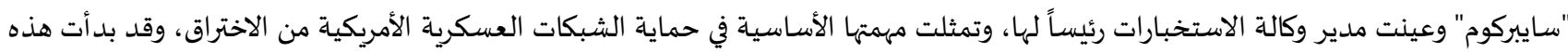

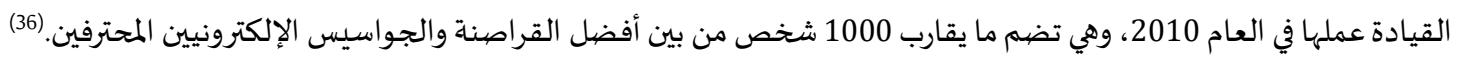

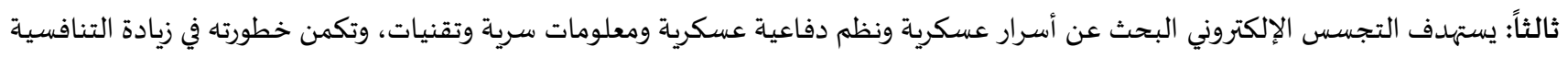

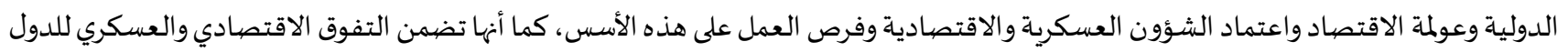

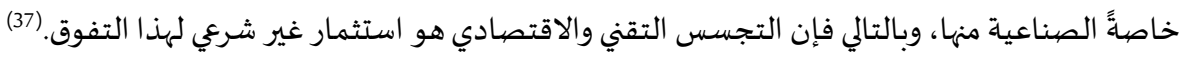

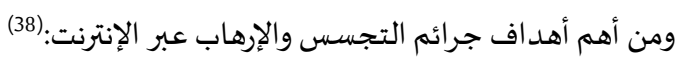

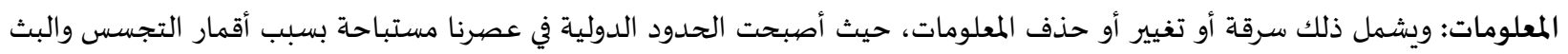

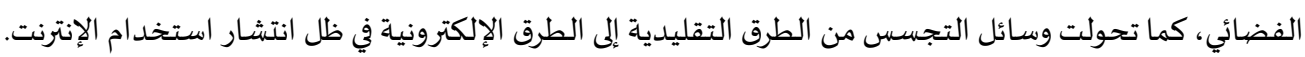
الأجهزة: ويتمثل ذلك في تعطيلها أو تخريبها.

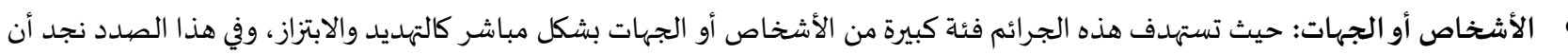

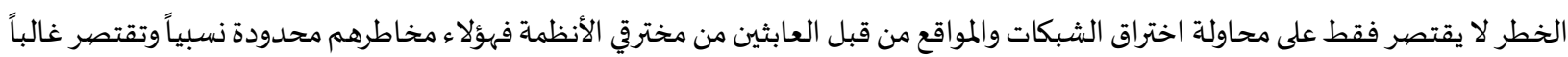

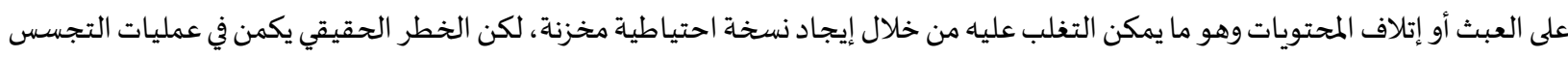

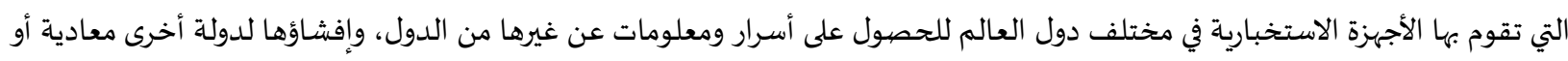

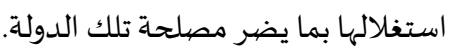

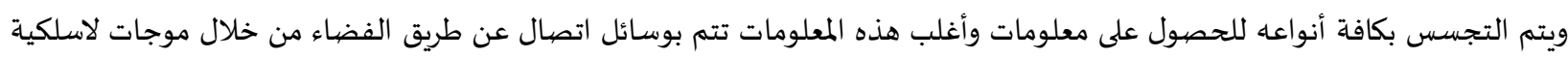

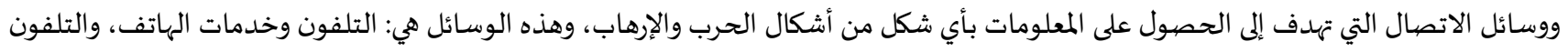

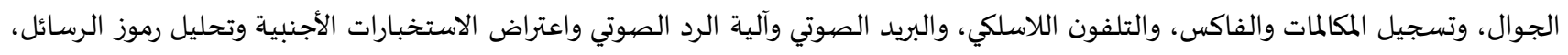
والإرسال بالساتلايت، والتنصت على المكالمات الهاتفية. (39)

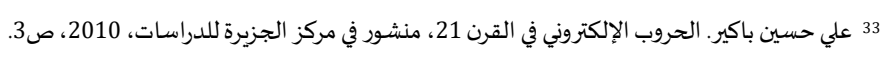

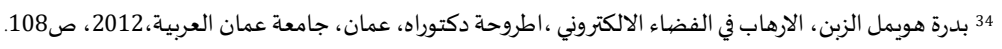

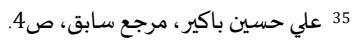

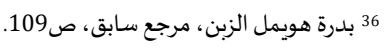

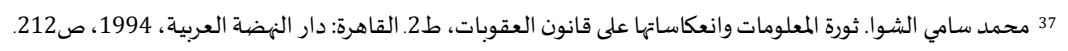

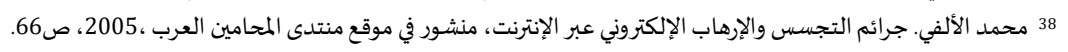

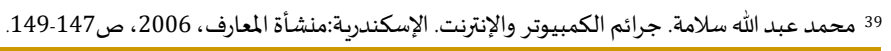




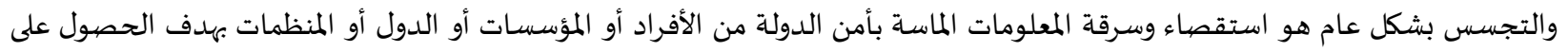

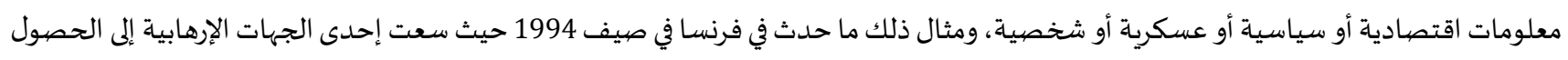

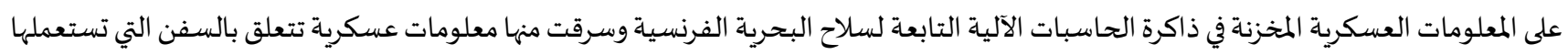

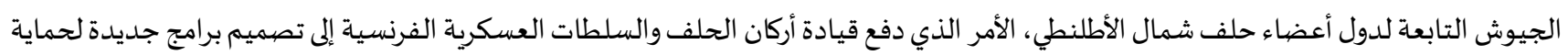

حاسباتها الآلية. (40)

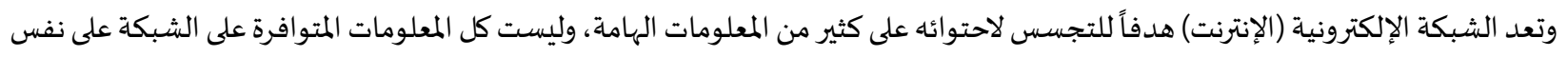

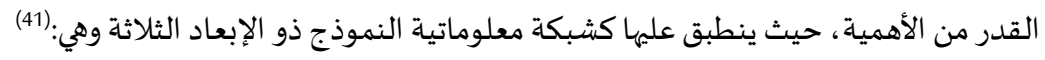

$$
\begin{aligned}
& \text { سرية المعلومات } \\
& \text { هلامة المعلومات } \\
& \text { وجود المعلومات } \\
& \text { رابعاً: التنكروالخفاء: }
\end{aligned}
$$

تتم حرب المعلومات من قبل المتنكرين والمختفين، فهم من يرتكب جرائم الكمبيوتر والإنترنت خلسـة وبكافة أشكالها وهم في حالة تنكر وخفاء، مثل

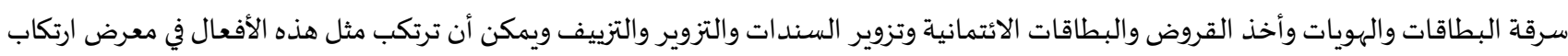
جرائم الإرهاب الإلكتروني. فهناك فيروسات تزرع في جهاز الخصم للدخول إليه وحذف الملفات الموجودة باه وإعادة تجهيز القرص الصيلب وتحول حصان طروان طروادة إلى قنبلة منطقية أو قنبلة وقت (42) وهناك وسائل لتدمير أجهزة الآخرين وإتلاف المعلومات عليها وهي: حصيان الخيان طروادة وأنواع من الفيروسات منها ما يتعلق بقطاع

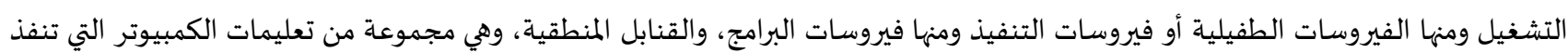

عملاً مؤذياً عند توفر شروط معينة. (43) خامساً: العمليات النفسية التي تتم بالمعلوماتياً وتعد هذه العمليات من المسائل الهامة والأساسية في الحرب الإلكترونية والإرهاب عبر الإنترنت وهي:ألمعلية:

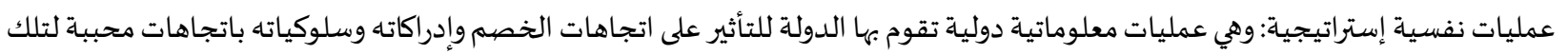

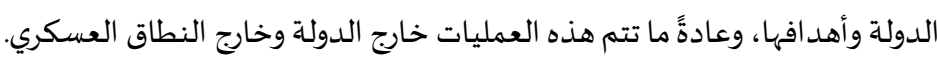
العمليات النفسية العملياتية: وهي التي تتم قبل الحرب وخلالها وأيام الصراعات وقد تكون موجهة لبقعة جفرافية معينة أثناء الصراعات المفتوحة. العمليات النفسية التكتيكية: وهي التي تنفذ في منطقة لقائد تكتيكي خلال الصراعات أو الحرب لدعم هدف تكتيكي ضيد الخصيم.

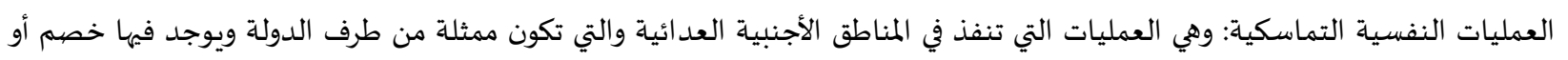
جماعات عدائية لها وتنفذ لإنتاج سلوكيات داعمة لأهد اف الدولية.

\section{المبحث الثالث: عوامل نجاح التنظيمات الإرهابية عبر الإنترنت}

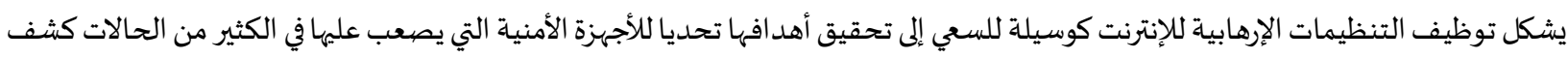

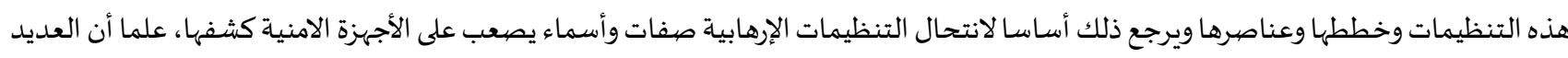
من هذه التنظيمات تستقطب متخصصين في المواقع الإلكترونية يتمتعون بالقدرة على المناورة والتخفي عن أعين الرقابة الأمنية. المطلب الأول: عوامل النجاح الناتجة عن خصيائص الإرهاب بحد ذاته

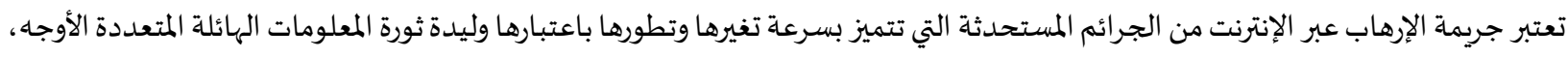
لهذا فإنها تختلف عن الجرائم العادية بعدد من الخصيائص: 


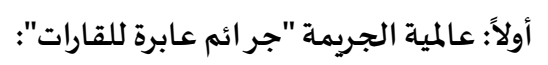

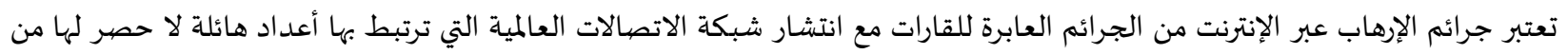

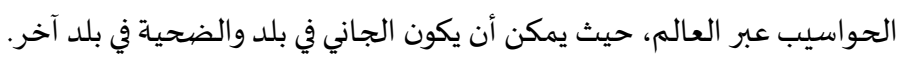

ثانياً: جر ائم صبعبة الإثبات:

تتميز بصعوبة متابعتها واكتشافها بحيث لا تترك الأثر الفوري والمباشر، فهي عبارة عن أرقام تتغير في السجلات الحاسوبية، فالكثير من هذه الجرائم

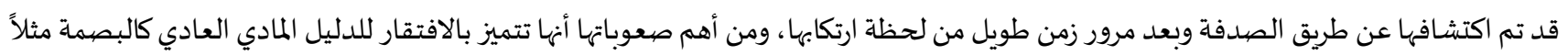

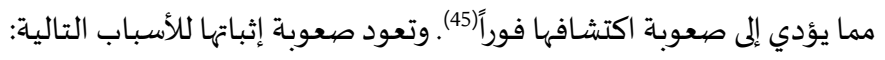

$$
\text { هي جريمة لا تترك أثرا بعد ارتكابها. }
$$

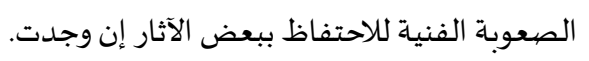

تحتاج إلى خبرة فنية من قبل مختصين، مما يصيّب على المحققين العاديين التعامل معها.

اعتمادها على الخدعة ومحاولة التضليل في التعريف بمرتكبيها.

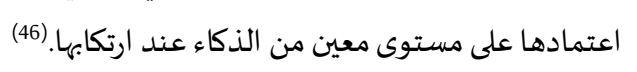

ثالثاً: الجر ائم الناعمة: أنماعل

إذا ما قورنت بالجرائم العادية التي تتطلب في حال ارتكابها المجههود العضلي مثل جرائم السرقة والقتل وغيرها فإن الجريمة الإلكترونية تعتمد اعتماداً

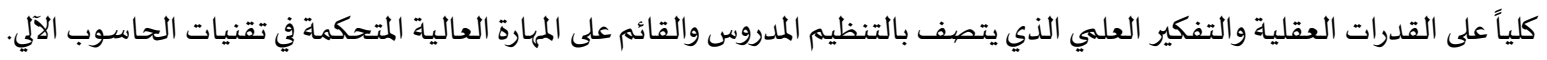

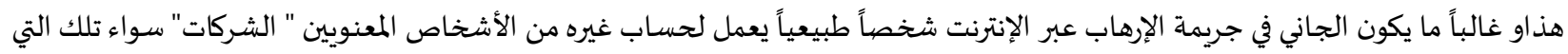

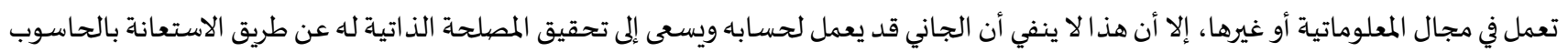
ومعالجة المعلومات. (47)

المطلب الثاني: عوامل النجاح ات الصلة بطبيعة وسمات المجرم الإلكتروني عبرشبكة الإنترنت

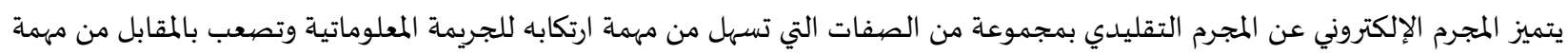

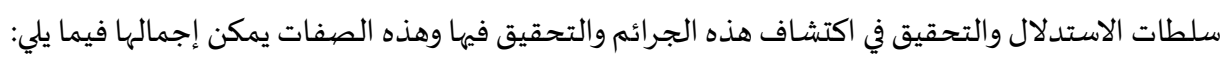
أولاً: الذكاء الإلكتروني: فالمجرم الإلكتروني يتسم بالذكاء العقلي المتميز في مجال المعلوماتية، ذلك أن السيطرة على النظام المعلوماتي والكمبيوتر والإنترنت تتطلب قدراً

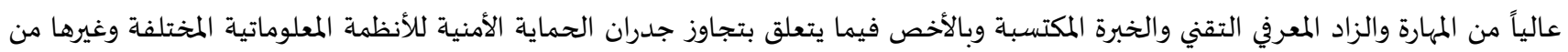

العقبات المعلوماتية التي قد تعترض سبيل ارتكاب الجانبي للجريمة المعلوماتية. (48)

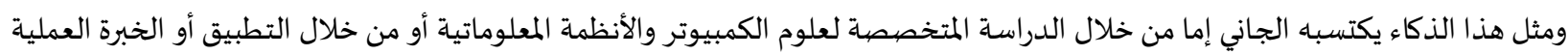

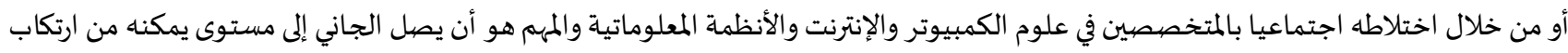

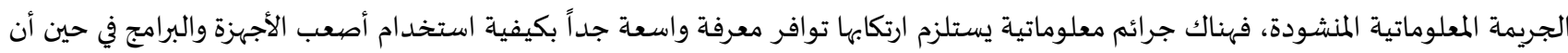

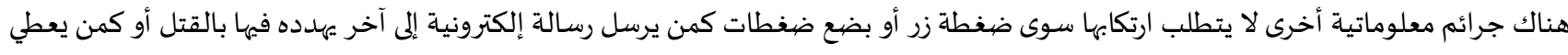

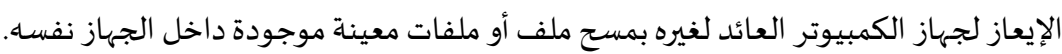

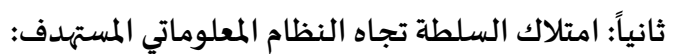

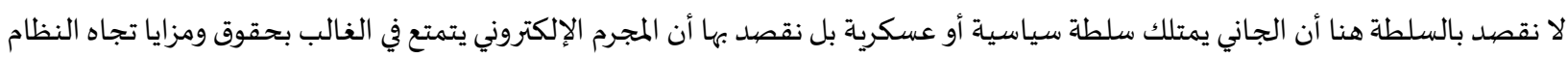

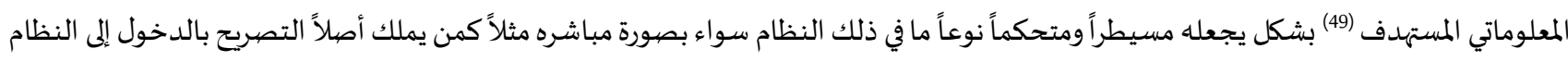

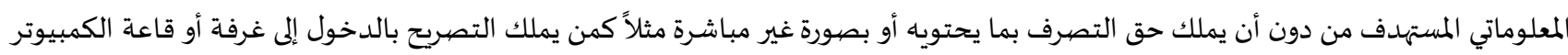
من دون أن يملك التصريح باستعمال ذلك الكمبيوتر أو كمن يملك التصريح باستعمال تلك الكمبيوترات ولكن من دون أن يملك الحق في الولوج إلى نظام

45 هشام رستم. الجرائم المعلوماتية، أصول التحقيق الجنائي، دبي، مجلة الأمن والقانون، العدد 2، 1999.

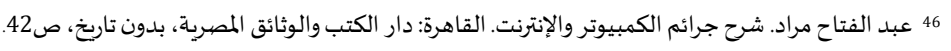

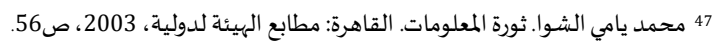

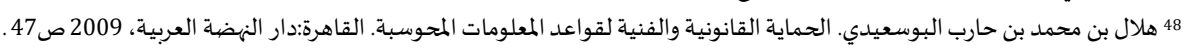
49 أحمد محمود مصطفي. جرائم الحاسبات الآلية في التشريع المصري. القاهرة: دار النهضية العربية، 2010 صان، 20 
معلوماتي معين، ونرى هنا بأن هذه السمة ليست مطلقة فهي لا تنطبق على الغير الذي يخترق النظام المعلوماتي لمؤسسـة معينة من خارج المؤسسـة ومن

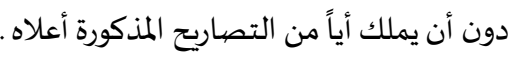

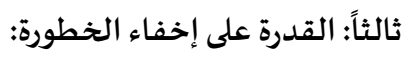

فالمجرم الإلكتروني يتسم بقدرته على إخفاء خطورتهاء عن مجتورة: إخعاه فهو يختلط مع مجتمعه ويحرص على عدم إظهار خطورته الإجرامية، ويطلق

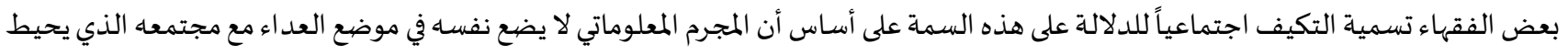

باه وأنها قادر على التكيف مع مجتمعاء. (50)

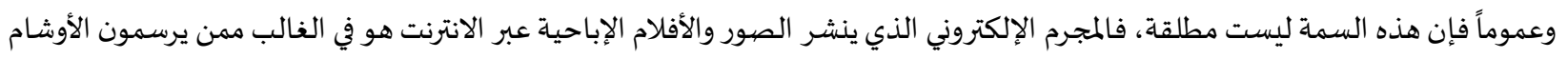

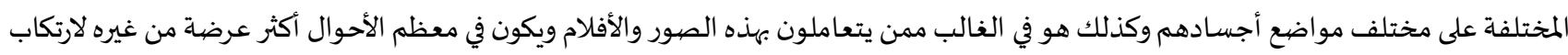

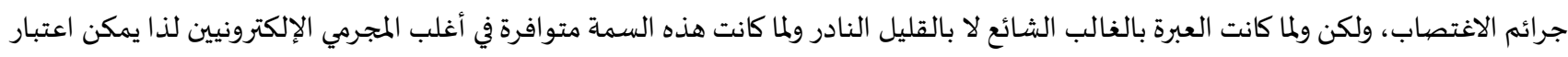

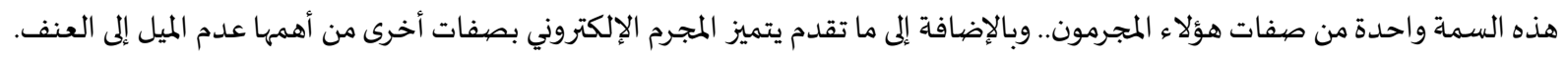

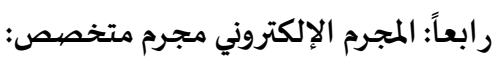

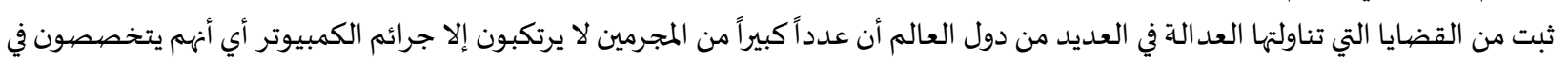
هذا النوع من الجرائم دون غيره.

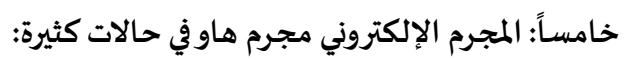

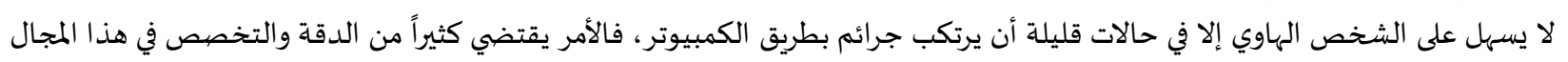

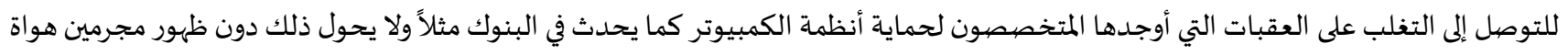

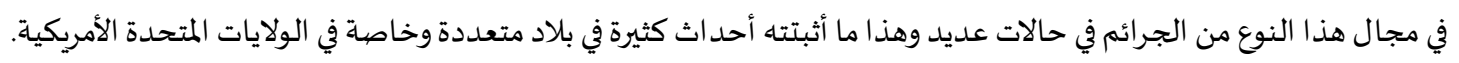
سادساً: المجرم الإلكتروني مجرم ذكي:

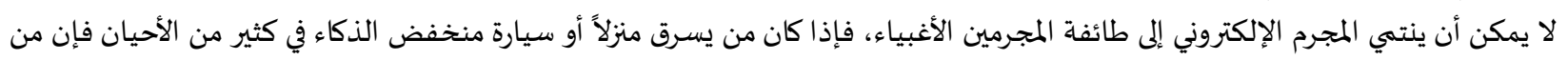

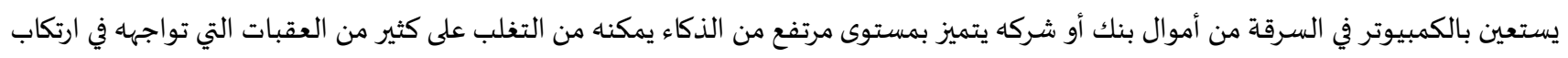

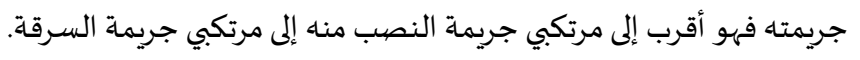

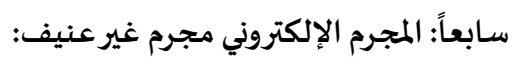

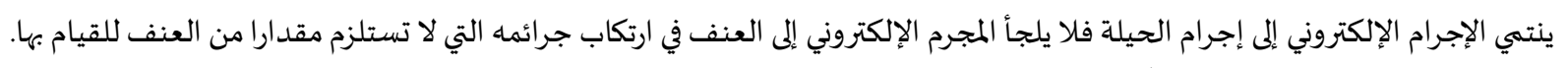
ثامناً: المجرم الإلكتروني متكيف اجتماعياً:

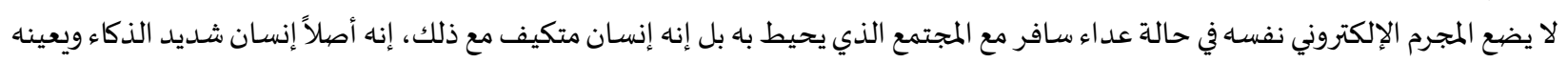

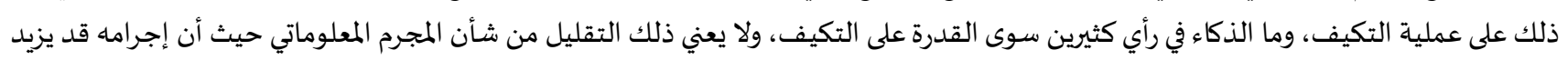

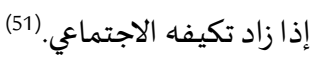

الخاتمة:

ثمة تخوف كبير على الصعيد العالمي من مستقبل الإرهاب الإلكتروني الذي تمارسه التنظيمات الإرهابية، ذلك الإرهاب الالكتروني مجهول الأبعاد

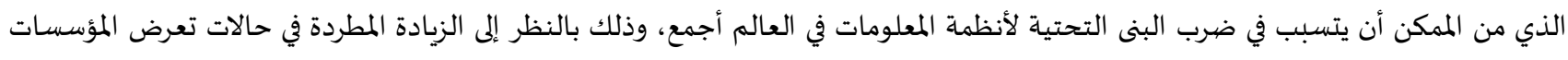

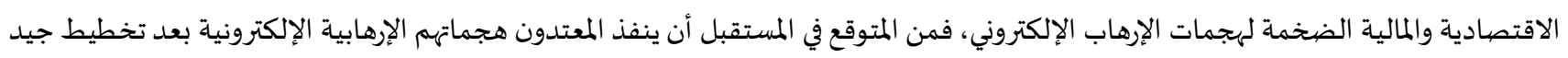

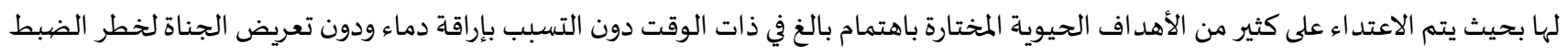

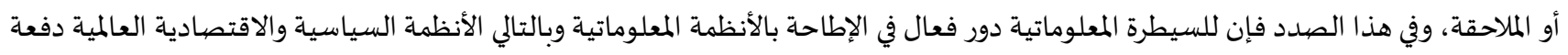

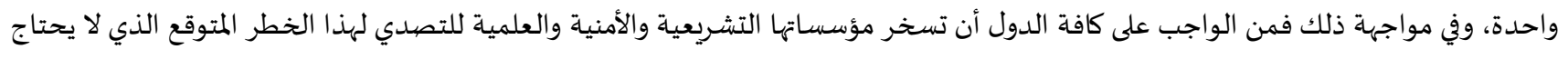
من الأدوات سوى إلى فأرة الكمبيوتر ولا يحتاج من جهد بغية التسبب بالتدمير الشامل سوى إلى نقرة خفيفة على هذه الفأرة.

50 عبد الفتاح بيومي حجازي. التزوير في جرائم الكمبيوتر والانترنت.القاهرة:دار الكتب القانونية، ص 212،213.

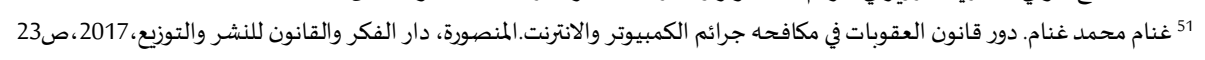


الإرهاب الإلكتروني صورة من صور الإرهاب التقليدي، وقد مر تعريف الإرهاب عبر العديد من المحاولات وخضع للأهواء السياسية للدول الكبرى

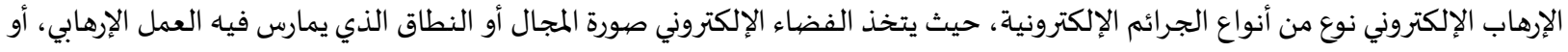

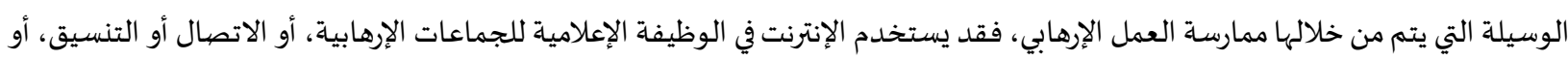
كوسيلة لتحقيق الأهداف الإرهابية.

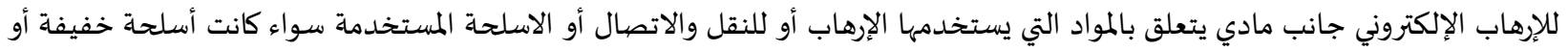

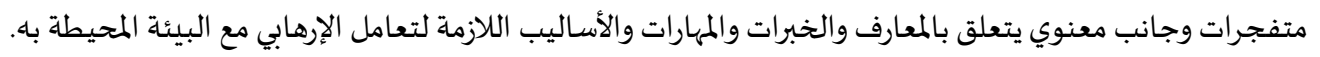

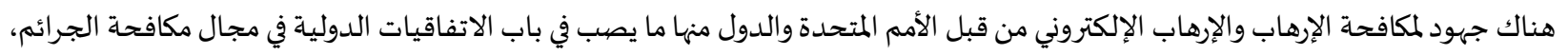

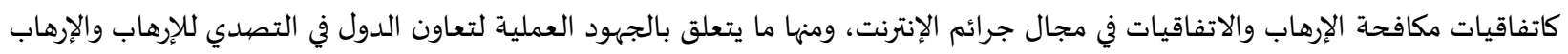

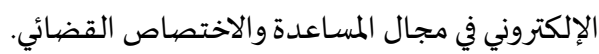
ثانياً: التوصيات:

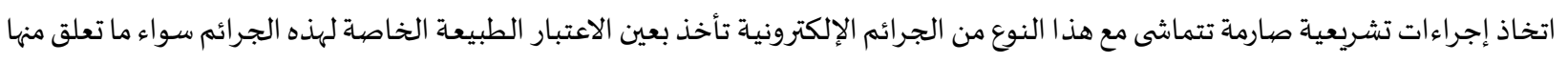

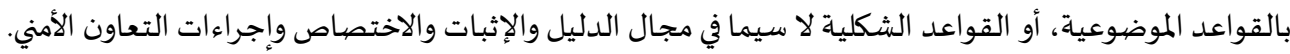

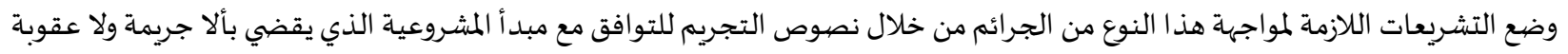
إلا بنص. ضرورة التنسيق والتعاون بين الدول على المستويات الإقليمية والدولية من النواحي القضائية والإجرائية.

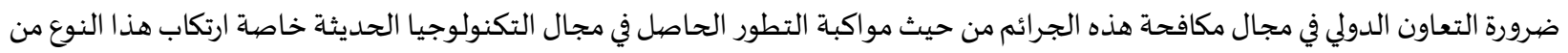

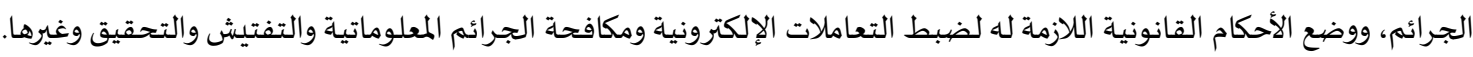

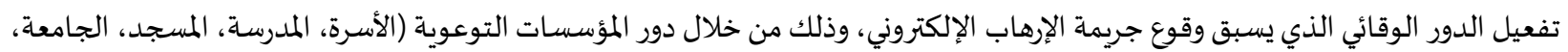

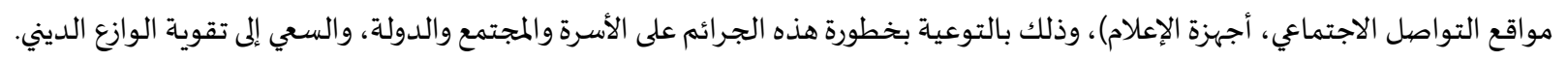

1. البداينة، ذياب (2002). الأمن وحرب المعلومات. عمان: دار الشروق للنشر والتوزيع. 2.

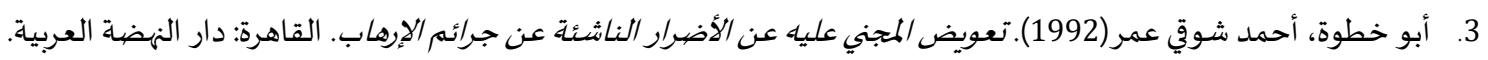

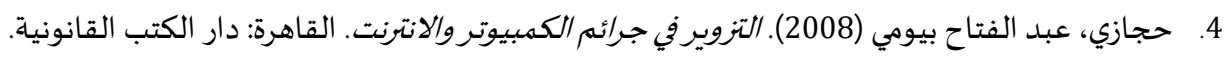

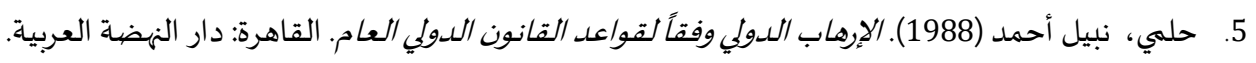

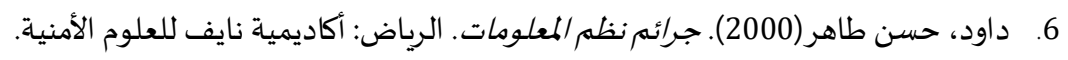
7. 8.

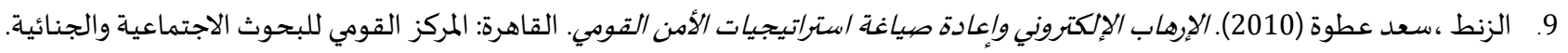

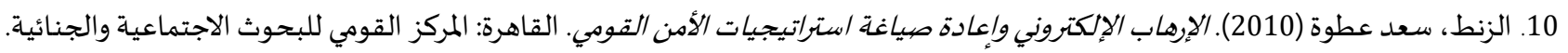

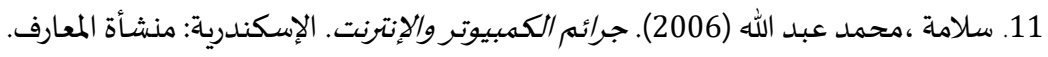

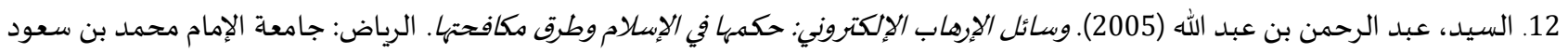
الإسلامية.

13. شكري، محمد عزيز، يازبي، أمل (2012). الإرهاب الدولي والنظام العالمي الراهن. دمشق: دار الفكر.

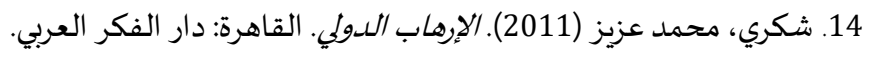
15. الشوا، محمد سامي (1994).ثورة المعلومات وانعكاساتها على قانون العقوبات. القاهرة: دار الهضية العربية. 
16. الشوا، محمد يامي (2003).ثورة المعلومات. القاهرة: مطابع الهيئة لدولية.

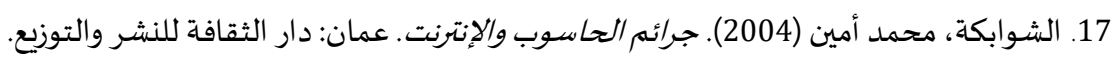

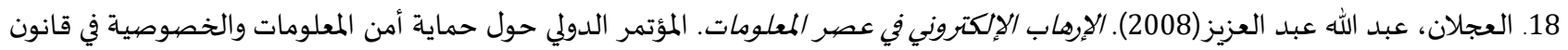
الإثبات. القاهرة: 4 - 2 يونيو.

19. عليان، رشدي (1998). الدين والإرهاب. بغداد: الإن منشورات منظمة المؤتمر الإسلامي الشعبي، بحوث فكرية للسنة الثالثة، كلية الشربعة. 20. غنام، غنام محمد (2017). دورقانون العقوبات في مكافحاه جرائم الكمبيوتر والانتونت. المنصيورة: دار الفكر والقانون للنشر والتوزيع. 21. الفريح، صالح. مواجهة جرائم التطرف والغلو والتكفير من خلال الإنتونت. الرياض: كلية الملك فهد الأمنية، ندوة المجتمع والأمن، الجرائم الإلكترونية. 22. الفيروز آبادي، مجد الدين محمد بن يعقوب، تحقيق مكتب تحقيق التراث في مؤسسة الرسالة 1994 ـ القاموس المحيط، بيروت: بدون ذكر دار

23. قاموس المنجد. (1969). القاهرة: دار الشروق.

24. القزويني، أحمد بن فارس (1979). معجمه مقاييس اللغة . بيروت :دار الفكر للنشر. 25. مختار المشرف، معنوي (2004). علاقة جريمة الإرهاب الإلكتروني بغيرها من الجرائم. ورقة عملة عل عن عن استخدام الحاسوب الآلي في مكافحة

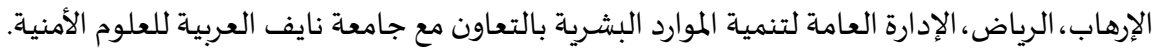
26. مذكور، إبراهيم وحجازي، مصطفى (1980). المعجم الوجيز. القاهرة مطابع شركة الإعلانات الشقية، دار الإدارة التحرير للطبع والنشر.

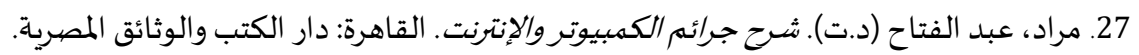
28. المري، جمال (2008).كيف نفهم الإرهاب؟ ابوظبي: مركز الامارات للدراسات والبحوث الاستراتيجية، 29. مسعود، جبران (1986). معتجم الرائد . بيروت: دار العلم للملايين.

30. المصري، مهران زهير (2011). الإرهاب الإلكتروني. منشور في موقع مجلة الباحثون الإلكتروني مجلة علمئلة المية فكرية شهرية.

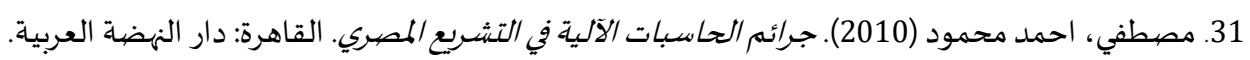

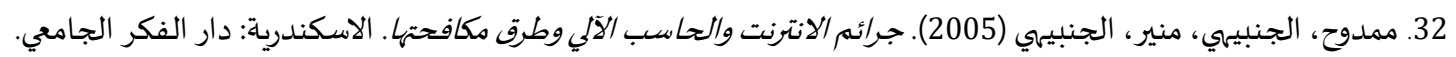

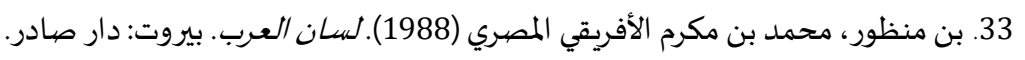

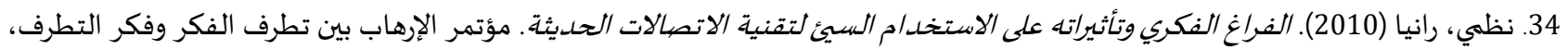
المدينة المنورة، الجامعة الإسلامية.

35. واصل، سامي جاد عبد الرحمن (2003). إرهاب الدولة في إطار القانون الدولي العام. الإسكندرية: منشأة المعارف .

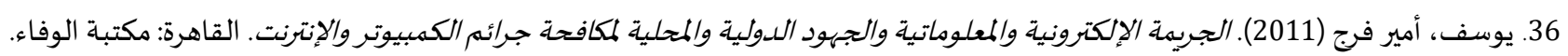

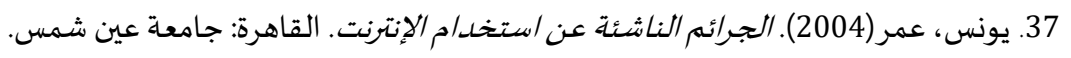

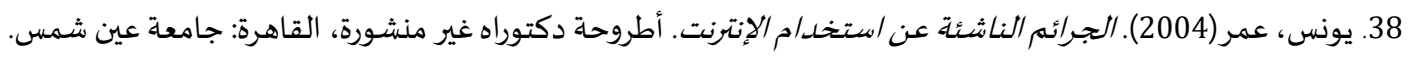
ثانياً: مقالات وتقارير:

1. الألفي، محمد (2005). جرائم التجسس والإرهاب الإلكتروني عبر الإنترنت. منشور في موقع منتدى المحامين العرب.

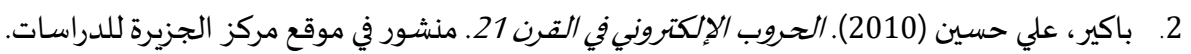

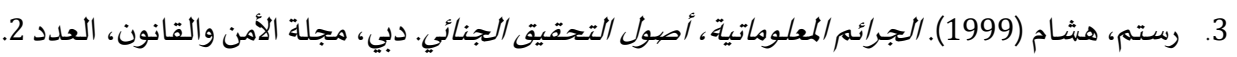

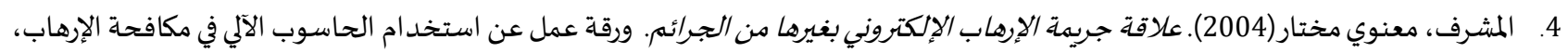
التي نظمتها الإدارة العامة لتنمية الموارد البشرية بالتعاون مع جامعة نايف العربية للعلوم الأمنية، شهر نيسان. 


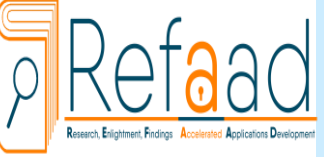

www.refaad.com
المجلة الدولية للدراسـات القانونية والفقهية المقارنة

International Journal of Legal and Comparative Jurisprudence Studies (LCJS)

Journal Homepage: https://www.refaad.com/views/LCJS/Home.aspx

ISSN: 2708-6607(Online) 2708-6593(Print)

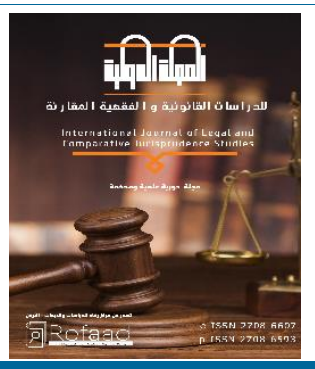

\title{
Methods and objectives of terrorist organizations via the Internet and their impact on international security
}

\author{
Kheireddine Laib \\ PHD in international relations-Algeria \\ Khiredine12@hotmail.com
}

\author{
Received: 12/5/2021 Revised: 20/6/2021 Accepted: 24/7/2021 DOI: https://doi.org/10.31559/LCJS2021.2.2.2
}

\begin{abstract}
The expansion and proliferation of terrorist organizations in our time poses a dilemma that concerns not only a specific society, region, community, or ethnic group, but all states of the world, whose security and stability have come under the blind threat of terrorism.

Methods of dealing with and dealing with terrorism have become one of the most important issues of multifaceted research concerned by the security and police agencies in developed and developing societies. Individuals, peoples, and states are increasingly concerned about the phenomenon of terrorism, which has become alarmingly expanding because of the wide spread of terrorist operations in recent years across the globe. terrorism is no longer limited to individual events of limited time and space. it is a very serious phenomenon that threatens the security and stability of nations, impedes the progress of various development plans, and threatens international peace and security.

The study aims to identify the goals of terrorist organizations and their methods through the use of technology and technology in their terrorist acts, the study has relied on the descriptive and analytical approach because it is the most appropriate approach to such studies, and concluded that cyber terrorism is a type of cybercrime more dangerous and deadly than conventional terrorism because it employs precise techniques and Phenomenon and the effects that threaten the security and stability of human society.
\end{abstract}

Keywords: Terrorism; cyber terrorism; terrorist organizations; the internet.

\section{References:}

1. Al'jlan, 'bd Allh 'bd Al'zyz(2008). Alerhab Alelktrwny Fy 'Esr Alm'lwmat. Alm'etmr Aldwly Hwl Hmayh Amn Alm'lwmat Walkhswsyh Fy Qanwn Alethbat. Alqahrh: 2-4 Ywnyw.

2. 'lyan, Rshdy (1998). Aldyn Walerhab. Bghdad: Mnshwrat Mnzmh Alm'tmr Aleslamy Alsh'by, Bhwth Fkryh Llsnh Althalthh, Klyt Alshry'h.

3. Albdaynh, Dyab (2002). Alamn Whrb Alm'lwmat. 'man: Dar Alshrwq Llnshr Waltwzy'.

4. Albws'ydy, Hlal Bn Mhmd Bn Harb (2009). Alhmayh Alqanwnyh Walfnyh Lqwa'd Alm'lwmat Almhwsbh. Alqahrh: Dar Alnhdh Al'rbyh.

5. Dawd, Hsn Tahr (2000). Jra'm Nzm Alm'lwmat. Alryad: Akadymyh Nayf Ll'lwm Alamnyh.

6. Alfryh, Salh. Mwajhh Jra'm Alttrf Walghlw Waltkfyr Mn Khlal Alentrnt. Alryad: Klyt Almlk Fhd Alamnyh, Ndwh Almjtm' Walamn, Aljra'm Alelktrwnyh.

7. Alfyrwz Abady, Mjd Aldyn Mhmd Bn Y'qwb, Thqyq Mktb Thqyq Altrath Fy M'sst Alrsalh 1994 . Alqamws Almhyt, Byrwt: Bdwn Dkr Dar Alnshr.

8. Ghnam, Ghnam Mhmd (2017). Dwr Qanwn Al'qwbat Fy Mkafht Jra'm Alkmbywtr Walantrnt. Almnswrh: Dar Alfkr Walqanwn Llnshr Waltwzy'.

9. Hjazy, 'bd Alftah Bywmy (2008). Altzwyr Fy Jra'm Alkmbywtr Walantrnt. Alqahrh: Dar Alktb Alqanwnyh. 
10. Hlmy, Nbyl Ahmd (1988). Alerhab Aldwly Wfqaan Lqwa'd Alqanwn Aldwly Al'am. Alqahrh: Dar Alnhdh Al'rbyh.

11. Abw Khtwh, Ahmd Shwqy 'mr(1992). T'wyd Almjny 'lyh 'n Aladrar Alnash'h 'n Jra'm Alerhab. Alqahrh: Dar Alnhdh Al'rbyh.

12. Mdkwr, Ebrahym Whjazy,Mstfa (1980). Alm'jm Alwjyz. Alqahrh Mtab' Shrkh Ale'lanat Alshqyh, Dar Althryr Lltb' Walnshr.

13. Mkhtar Almshrf, M'nwy (2004). 'laqh Jrymh Alerhab Alelktrwny Bghyrha Mn Aljra'm. Wrqh 'ml 'n Astkhdam Alhaswb Alaly Fy Mkafht Alerhab,Alryad,Aledarh Al'amh Ltnmyh Almward Albshryh Balt'awn M' Jam't Nayf Al'rbyh Ll'lwm Alamnyh.

14. Mrad, 'bd Alftah (D.T). Shrh Jra'm Alkmbywtr Walentrnt. Alqahrh: Dar Alktb Walwtha'eq Almsryh.

15. Almry, Jmal (2008). Kyf Nfhm Alerhab? Abwzby: Mrkz Alamarat Lldrasat Walbhwth Alastratyjyh,

16. Ms'wd, Jbran (1986). M'jm Alra'd . Byrwt: Dar Al'Im Llmlayyn.

17. Almsry, Mhran Zhyr (2011). Alerhab Alelktrwny. Mnshwr Fy Mwq' Mjlt Albahthwn Alelktrwny Mjlt 'lmyh Fkryh Shhryh.

18. Qamws Almnjd. (1969). Alqahrh: Dar Alshrwq.

19. Alqzwyny,Ahmd Bn Fars (1979). M'jm Mqayys Allghh. Byrwt: Dar Alfkr Llnshr.

20. Alrazy, Mhmd Bn Aby Bkr(1988). Mkhtar Alshah. Byrwt: Mktbh Lbnan.

21. Shkry, Mhmd 'zyz, Yazjy, Aml (2012). Alerhab Aldwly Walnzam Al'almy Alrahn. Dmshq: Dar Alfkr.

22. Shkry, Mhmd 'zyz (2011). Alerhab Aldwly. Alqahrh: Dar Alfkr Al'rby.

23. Alshwa, Mhmd Samy (1994). Thwrh Alm'lwmat Wan'kasatha 'la Qanwn Al'eqwbat. Alqahrh: Dar Alnhdh Al'rbyh.

24. Alshwa, Mhmd Yamy (2003). Thwrh Alm'lwmat. Alqahrh: Mtab' Alhy'h Ldwlyh.

25. Alshwabkh, Mhmd Amyn (2004). Jra'm Alhaswb Walentrnt. 'man: Dar Althqafh Llnshr Waltwzy'.

26. Slamh, Mhmd 'bd Allh (2006). Jra'm Alkmbywtr Walentrnt. Aleskndryh: Mnshat Alm'arf.

27. Alsyd, 'bd Alrhmn Bn 'bd Allh (2005). Wsa'l Alerhab Alelktrwny: Hkmha Fy Aleslam Wtrq Mkafhtha. Alryad: Jam't Alemam Mhmd Bn S'wd Aleslamyh.

28. Alzbn, Bdrh Hwyml (2012). Alarhab Fy Alfda' Alelktrwny. Atrwhh Dktwrah, 'man, Jam't 'man Al'rbyh.

29. Alznt ,S'd 'twh (2010). Alerhab Alelktrwny We'adh Syaghh Astratyjyat Alamn Alqwmy. Alqahrh: Almrkz Alqwmy Llbhwth Alajtma'yh Waljna'yh.

30. Alznt, S'd 'twh (2010). Alerhab Alelktrwny We'adh Syaghh Astratyjyat Alamn Alqwmy. Alqahrh: Almrkz Alqwmy Llbhwth Alajtma'yh Waljna'eyh. 